\title{
The APP Intracellular Domain Is Required for Normal Synaptic Morphology, Synaptic Plasticity, and Hippocampus-Dependent Behavior
}

\author{
Maja Klevanski, ${ }^{1 *}$ Ulrike Herrmann, ${ }^{2 *}$ Sascha W. Weyer, ${ }^{1 *}$ Romain Fol, ${ }^{3,4}$ Nathalie Cartier, ${ }^{3}$ DDavid P. Wolfer, ${ }^{5}$ \\ John H. Caldwell, ${ }^{6}$ Martin Korte, ${ }^{2,7}$ and Ulrike C. Müller ${ }^{1}$ \\ ${ }^{1}$ Department of Bioinformatics and Functional Genomics, Institute of Pharmacy and Molecular Biotechnology, Heidelberg University, 69120 Heidelberg, \\ Germany, ${ }^{2}$ Zoological Institute, TU Braunschweig, 38106 Braunschweig, Germany, ${ }^{3}$ INSERM U1169/MIRCen CEA Fontenay aux Roses, 92265 , and \\ Université Paris-Sud, University Paris-Saclay, Orsay 94100, France, ${ }^{4}$ Université Paris Descartes, 75006 Paris, France, ${ }^{5}$ Institute of Anatomy, University of \\ Zurich and Institute of Human Movement Sciences, ETH Zurich, 8057 Zurich, Switzerland, ${ }^{6}$ Department of Cell and Developmental Biology, University of \\ Colorado, Aurora, Colorado 80045, and ${ }^{7}$ AG NIND, Helmholtz Centre for Infection Research, 38124 Braunschweig, Germany
}

The amyloid precursor protein family (APP/APLPs) has essential roles for neuromuscular synapse development and for the formation and plasticity of synapses within the CNS. Despite this, it has remained unclear whether APP mediates its functions primarily as a cell surface adhesion and signaling molecule or via its numerous proteolytic cleavage products. To address these questions, we followed a genetic approach and used APP $\triangle$ CT15 knockin mice lacking the last 15 amino acids of APP, including the highly conserved YENPTY protein interaction motif. To circumvent functional compensation by the closely related APLP2, these mice were bred to an APLP2-KO background to generate APP $\Delta$ CT15-DM double mutants. These APP $\Delta$ CT15-DM mice were partially viable and displayed defects in neuromuscular synapse morphology and function with impairments in the ability to sustain transmitter release that resulted in muscular weakness. In the CNS, we demonstrate pronounced synaptic deficits including impairments in LTP that were associated with deficits in spatial learning and memory. Thus, the APP-CT15 domain provides essential physiological functions, likely via recruitment of specific interactors. Together with the well-established role of APPs $\alpha$ for synaptic plasticity, this shows that multiple domains of APP, including the conserved C-terminus, mediate signals required for normal PNS and CNS physiology. In addition, we demonstrate that lack of the APP-CT15 domain strongly impairs A $\beta$ generation in vivo, establishing the APP C-terminus as a target for A $\beta$-lowering strategies.

Key words: Alzheimer's disease; amyloid precursor protein; behavior; knockin; signaling; synaptogenesis

Significance Statement

Synaptic dysfunction and cognitive decline are early hallmark features of Alzheimer's disease. Thus, it is essential to elucidate the in vivo function(s) of APP at the synapse. At present, it is unknown whether APP family proteins function as cell surface receptors, or mainly via shedding of their secreted ectodomains, such as neurotrophic APPs $\alpha$. Here, to dissect APP functional domains, we used APP mutant mice lacking the last 15 amino acids that were crossed onto an APLP2-K0 background. These APP $\Delta$ CT15-DM mice showed defects in neuromuscular morphology and function. Synaptic deficits in the CNS included impairments of synaptic plasticity, spatial learning, and memory. Collectively, this indicates that multiple APP domains, including the C-terminus, are required for normal nervous system function.

\section{Introduction}

The amyloid precursor protein (APP) is central to the pathogenesis of Alzheimer's disease (AD), as APP processing gives rise to $\mathrm{A} \beta$ peptides accumulating in the brains of $\mathrm{AD}$ patients. Preceding plaque deposition, $\mathrm{AD}$ is characterized by diminished synaptic contacts that are correlated with cognitive deficits. It is therefore crucial to elucidate the normal in vivo role of APP at the synapse 
and to assess whether loss of physiological APP functions contributes to $\mathrm{AD}$ pathogenesis.

APP belongs to a gene family that comprises, in addition to APP, the two amyloid precursor-like proteins, APLP1 and APLP2. Although the A $\beta$ domain is unique for APP, APLPs undergo similar processing by $\alpha$-, $\beta$-, and $\gamma$-secretases (Aydin et al., 2012). APP and APLPs are highly expressed in brain, including hippocampus, and are localized to postsynaptic and presynaptic sites both at the neuromuscular junction (Wang et al., 2009; Caldwell et al., 2013; Klevanski et al., 2014) and at CNS synapses (Laßek et al., 2013; Wilhelm et al., 2014). APP family proteins have been implicated in numerous processes, including transcription, neuronal differentiation and migration, neurite outgrowth, and synaptogenesis. Presently, it is not clear whether APP family proteins mainly function as surface-bound synaptic signaling receptors and/or adhesion molecules (Wang et al., 2009; Baumkötter et al., 2014; Bourdet et al., 2015) or act through their shedded ectodomains, such as APPs $\alpha$, that have well-established functions in neuroprotection (Kögel et al., 2012) and in synaptic plasticity (Taylor et al., 2008; Korte et al., 2012; Hick et al., 2015). The APP C-terminus contains highly conserved protein interaction domains, notably the YENPTY motif that mediates APP internalization and was reported to regulate APP trafficking, processing, and likely signaling (Aydin et al., 2012; van der Kant and Goldstein, 2015). Moreover, this motif binds numerous cytosolic proteins, including Dab1, Shc, Grb, Mint/X11 proteins, and Fe65 family proteins (Aydin et al., 2012; van der Kant and Goldstein, 2015). The in vivo relevance of conserved APP domains, however, including the relevance of the multitude of interactors has remained challenging to dissect, as APP functions may be compensated by APLPs. Mice lacking single APP family members are viable, whereas APP/APLP2 double knock-out (DKO) or APLP1/ APLP2-DKO mice die perinatally (Magara et al., 1999; Heber et al., 2000; Herms et al., 2004) due to impaired neuromuscular transmission (Wang et al., 2005; Weyer et al., 2011; Caldwell et al., 2013; Klevanski et al., 2014). Recently, we generated conditional DKO mice ( $\mathrm{CDKO}$ mice) lacking APP in excitatory forebrain neurons (Hick et al., 2015). These fully viable cDKO mice revealed a crucial role of APP family proteins for dendritic length and branching, spine density, synaptic plasticity, and hippocampus-dependent behavior (Hick et al., 2015). While these studies corroborated essential in vivo functions of APP/ APLP2 also in the CNS, crucial questions remained: which APP domain(s) or proteolytic fragments are required to mediate these functions and which signaling pathways are involved? To dissect APP functional domains, we previously generated C-terminally truncated APP knockin (KI) alleles: APPs $\alpha$-KI mice produce only APPs $\alpha$, whereas APP $\Delta$ CT15-KI mice lack the last 15 amino acids, including the YENPTY motif (Ring et al., 2007). Interestingly, both KI lines showed a WT-like phenotype and lacked the impairments in LTP and behavior seen in APP-KO mice. These and other studies (Hornsten et al., 2007; Wentzell et al., 2012) suggested that APP functions are primarily mediated by the secreted fragment APPs $\alpha$. However, analysis of APPs $\alpha$-DM (double mu-

\footnotetext{
assistance; Paul Mathews for kindly providing the M3.2 and C1/6.1 antibody; and the Nikon Imaging Center (University of Heidelberg) for support with confocal microscopy.

The authors declare no competing financial interests.

*M.K., U.H., and S.W.W. contributed equally to this work.

Correspondence should be addressed to Dr. Ulrike C. Müller, Department of Bioinformatics and Functional Genomics, Institute of Pharmacy and Molecular Biotechnology, Heidelberg University, 69120 Heidelberg, Germany. E-mail: u.mueller@urz.uni-hd.de.

DOI:10.1523/JNEUROSCI.2009-15.2015

Copyright $\odot 2015$ the authors $\quad 0270-6474 / 15 / 3516019-16 \$ 15.00 / 0$
}

tants) obtained by crossing APPs $\alpha$-KI with APLP2-KO mice revealed a more complex picture (Weyer et al., 2011). To test whether C-terminal APP domains may be required for APP functions, we now generated double mutant mice (APP $\triangle \mathrm{CT} 15-\mathrm{DM}$ ) that lack APLP2 and the last 15 amino acids of APP. Similarly to APPs $\alpha$-DM mice, APP $\Delta$ CT15-DM mice proved partially viable and showed aberrant morphology of neuromuscular synapses, defective transmitter release, and muscular weakness. Pronounced synaptic deficits in the CNS included impairments of synaptic plasticity and hippocampus-dependent behavior. Collectively, this indicates that the APP-CT15 domain provides essential functions, likely via recruitment of specific proteins mediating signals required for normal PNS and CNS physiology.

\section{Materials and Methods}

Mice. APP-KO (Li et al., 1996), APPACT15-KI (Ring et al., 2007), APLP2-KO mice (von Koch et al., 1997), and APP/APLP2-DKO mice (Heber et al., 2000) were described previously. Briefly, APP $\Delta$ CT15-KI mice expressing a truncated form of APP that lacks the last $15 \mathrm{C}$-terminal amino acids were generated by inserting a stop codon into the terminal part of APP exon 18. APP ${ }^{-1-}$ APLP2 ${ }^{-1-}$ (APP/ALP2-DKO) and $\mathrm{APP}^{\Delta / \Delta} \mathrm{APLP}^{-1-}(\mathrm{APP} \Delta \mathrm{CT} 15-\mathrm{DM})$ mice were generated by intercrossing $\mathrm{APP}^{+/-} \mathrm{APLP}^{-/-}$or $\mathrm{APP}^{\Delta /+} \mathrm{APLP}^{-/-}$mice, respectively. $\mathrm{APP} \triangle \mathrm{CT} 15-\mathrm{DM}$ mice were genotyped using primers reported previously (Ring et al., 2007). Survival of APP $\Delta$ CT15-DM and APP/APLP2-DKO mice backcrossed to C57BL/6 animals either once (R1) or at least six times (R6) was determined at weaning. To assess the genotype distribution, $\chi^{2}$ test was applied. Mice used for phenotyping were backcrossed to $\mathrm{C} 57 \mathrm{BL} / 6$ animals for at least six generations (R6).

Measurement of $A \beta$. Mice were killed by $\mathrm{CO}_{2}$ euthanasia and immediately perfused transcardially with PBS $(0.1 \mathrm{M}, \mathrm{pH} 7.4)$. The brain was dissected, the olfactory bulbs and the cerebellum were removed, and both hemispheres were separated. The tissue was shock-frozen in liquid nitrogen and kept at $-80^{\circ} \mathrm{C}$ until use. For brain homogenates, a Tris-buffered saline-based lysis buffer (20 mM Tris-base, pH 7.4, $150 \mathrm{~mm} \mathrm{NaCl}, 1 \%$ Triton X-100) containing protease (Complete, Roche) and phosphatase inhibitors (PhosSTOP, Roche) was used. Mouse brain hemispheres were homogenized using a Potter homogenizer and centrifuged at $15,700 \times g$ for $20 \mathrm{~min}$. Supernatant was used for further analysis. Total protein was determined using BCA method, and homogenates were adjusted to 10 mg protein per milliliter. Mouse brain $\mathrm{A} \beta_{40}$ and $\mathrm{A} \beta_{42}$ levels were measured by electrochemiluminescence using the V-Plex $A \beta$ Panel kit from Meso Scale Discovery. The assay was performed as outlined by the manufacturer's instructions. Statistical significance was calculated using oneway ANOVA followed by Tukey's multiple-comparison test. Number of animals: WT, $n=5$; APLP2-KO, $n=6$; APPDCT15-DM, $n=6$. Age at analysis: 5-6 months, all male.

Western blot analysis. For Western blot analysis, specific antibodies directed against full-length APP and APPs $\alpha$ (M3.2; 1:1000; kind gift from Paul Mathews), the APP C-terminus (C1/6.1; 1:1000; provided by Paul Mathews), APPs $\beta$ (IBL, \#JP18957), and $\beta$-tubulin (MAB3408; 1:10,000; Millipore) were used. Brain dissection was done as described above. Mouse brain hemispheres were homogenized in tissue homogenization buffer ( $20 \mathrm{~mm}$ Tris-HCl, pH 7.4, $250 \mathrm{~mm}$ sucrose, $1 \mathrm{~mm}$ EDTA, $1 \mathrm{~mm}$ EGTA), including phosphatase and protease inhibitors (Roche) using a Potter homogenizer. After homogenization, a brief low-speed spin $(5000 \times g, 5 \mathrm{~min})$ was performed to remove remaining tissue fragments. For the detection of the soluble fragments APPs $\alpha$ and APPs $\beta$, a highspeed centrifugation step $(60 \mathrm{~min}$ at $100,000 \times g)$ was performed, and membrane-free supernatant was used for further analysis. Total brain homogenate (30 $\mu$ g protein) or supernatant (20 $\mu$ g protein) was used for SDS-PAGE using $4-12 \%$ Bis-Tris gels (Novex). For the detection of APP $\beta$-CTFs, the membrane pellet of the high-speed centrifugation ( $60 \mathrm{~min}$ at $100,000 \times g$ ) was solubilized in $1 \%$ Triton X-100. Proteins were separated by PAGE using 10-20\% Tris-Tricine gradient gels (Novex, Invitrogen). After blocking in 5\% nonfat milk powder in PBS-T for $1 \mathrm{~h}$, membranes were incubated with primary antibodies at $4^{\circ} \mathrm{C}$ overnight. 
M3.2 was used to detect full-length APP, APPs $\alpha$, and $\beta$-CTFs. Western blot signals were detected by enhanced chemiluminescence (Super Signal West Pico, Pierce or for $\beta$-CTFs with SignalFire, Synaptic Systems) and imaged using the ChemiDoc Imaging System (Bio-Rad). For quantification, all images were analyzed with the ImageLab software (Bio-Rad).

Immunohistochemistry and microscopy. Diaphragms of adult (2 months old) WT, APLP2-KO, and APP $\Delta$ CT15-DM mice were obtained and stained as previously described (Weyer et al., 2011). To avoid tissue stretching, the following procedures (up to the permeabilization step) were performed when the diaphragm muscle was still present within the dissected costal arch. Briefly, tissue was incubated in $1 \mathrm{mg} / \mathrm{ml}$ Type IA collagenase (Sigma-Aldrich) in PBS supplemented with $0.036 \mathrm{~mm} \mathrm{CaCl}_{2}$ for $15 \mathrm{~min}$ at room temperature (RT), rinsed in PBS, and fixed in $1 \%$ formaldehyde/PBS for $1 \mathrm{~h}$ at RT. After applying $0.1 \mathrm{M}$ glycine blocking solution overnight at $4^{\circ} \mathrm{C}$, tissue was permeabilized in $1 \%$ Triton $\mathrm{X}-100 /$ PBS ( $6 \mathrm{~h}$ at RT). Subsequently, the diaphragm muscle was excised along the border of the costal arch, and tissue was permeabilized (1\% Triton $\mathrm{X}-100 / \mathrm{PBS})$ and incubated with synaptophysin antibody (1:50; rabbit polyclonal, Invitrogen) in $2 \% \mathrm{BSA} / \mathrm{PBS}$ at $4^{\circ} \mathrm{C}$ for $48 \mathrm{~h}$. After three washing steps in PBS, the diaphragm was stained with MFP-488conjugated goat $\alpha$-rabbit antibody (1:100; Molecular Biotechnology) and rhodamine-conjugated $\alpha$-bungarotoxin (1:500; Invitrogen) in 2\% $\mathrm{BSA} / \mathrm{PBS}$ at $4^{\circ} \mathrm{C}$. For newborn mice, a modified protocol was used (Klevanski et al., 2014). The costal arch containing the diaphragm muscle was dissected from P0 mice and fixed for $15 \mathrm{~min}$ in $1 \%$ formaldehyde/ PBS solution at RT. Tissue was briefly rinsed in PBS and incubated for $2.5 \mathrm{~h}$ in $0.1 \mathrm{M}$ glycine blocking solution at RT. The diaphragm muscle was dissected from the costal arch, permeabilized with $1 \%$ Triton X-100/PBS for $10 \mathrm{~min}$ at RT, and incubated with the primary antibody solution (see above) overnight at $4^{\circ} \mathrm{C}$. The diaphragm was rinsed in PBS, and the solution containing the secondary antibody and the labeled bungarotoxin was applied overnight at $4^{\circ} \mathrm{C}$. After the staining procedure, diaphragms from both adult and newborn mice were washed in PBS and mounted in Mowiol 4-88 (Carl Roth). Images were obtained with a Nikon A1 laser scanning confocal microscope.

Quantification of synapse distribution. The endplate analysis was performed as described previously (Klevanski et al., 2014). As a baseline for further quantitative analyses, we determined the left-right (lr) extension of the diaphragm. For this, we acquired nonconfocal overview images in the channel used for synaptophysin (newborn pups) or neurofilament staining (adult animals). For the subsequent determination of the precise position of the synapse band relative to the inner border of the muscle, we also acquired overview images in the bungarotoxin channel (AChRs). Subsequently, the confocal maximum projection of the synapse band was superimposed onto the nonconfocal overview images (bungarotoxin channel) using well-discernible synapses as guideposts. The lr extension parameter corresponds to the distance between the inner muscle border of the diaphragm and the regression line of the synapse band (see below). Confocal image stacks were obtained in the bungarotoxin channel using a $20 \times$ objective (NA: 0.7; $z$-step: $1.5 \mu \mathrm{m}$ ) for tissue from P0 mice or $10 \times$ objective (NA: $0.45 ; z$-step: $2 \mu \mathrm{m}$ ) for adult mice and projected into one plane. Multiple maximum intensity projections were merged to one large image using ImageJ (National Institutes of Health) software. For the analysis of newborn mice, we selected a $728 \mu \mathrm{m}$ high region within the left hemidiaphragm (S2), located $\sim 550 \mu \mathrm{m}$ ventral to the entry point of the phrenic nerve (see also Klevanski et al., 2014). To obtain a comparable area in adult mice, the region was scaled and positioned accordingly. The coordinates of individual synapses were determined and imported to Excel software (Microsoft). A regression line describing the backbone of the synapse band was determined using a least squares linear fit. To quantify the area covered by AChR clusters, the region selected for analysis was subdivided into 8 segments oriented perpendicularly to the synapse band regression line. Subareas were calculated within each segment as a product of the segment height and the width determined by the most distal synapses within each segment. Total synapse band area was calculated as the sum of the 8 resulting subareas. Synapse density was calculated as number of synapses per subarea. To determine the width of the synapse band, 8 equidistant narrow segments (height: $\sim 1 / 5$ th of the height used for the subarea determination) were positioned perpendic- ularly to the regression line of the synapse band. The width was determined by the most distant synapses within each segment. The average band width was calculated from these 8 segments. At least 4-7 mice were examined per genotype. To account for differences in diaphragm size, all data were normalized according to the diaphragm extension parameters described above. Comparison of group means was performed using oneway ANOVA with Bonferroni post hoc test.

Quantification of synapse morphology. Morphological analysis of individual synapses was performed within the ventral part of the right hemidiaphragm (S3) as previously described (Klevanski et al., 2014). In brief, confocal image stacks ( $z$-step: $0.25 \mu \mathrm{m}$ ) were obtained using a $60 \times$ oilimmersion objective (NA: 1.4) and merged into maximum intensity projections. Only en face images of endplates were used to determine the area of presynaptic and postsynaptic specializations. Area of AChR clusters was measured using the "Particle Analyzer" tool of ImageJ. Synaptophysin area was quantified within the border of the AChR-occupied region. Degree of synaptophysin-AChR colocalization was determined using Manders' overlap coefficient described by Dunn et al. (2011) using the "Colocalization Analysis" tool of ImageJ. At least 10-20 synapses were analyzed from each mouse, and 4-7 animals were examined per genotype. Comparison of group means was performed using one-way ANOVA with Bonferroni post hoc test.

PNS electrophysiology. Electrophysiological recordings were performed as previously described (Ring et al., 2007; Weyer et al., 2011). Briefly, the diaphragm with $5-10 \mathrm{~mm}$ of the attached phrenic nerve was dissected from adult mice (6-7 weeks old), mounted in a Sylgard-lined dish, and superfused with oxygenated $\left(95 \% \mathrm{O}_{2}, 5 \% \mathrm{CO}_{2}\right)$ modified Tyrode's solution (in mu as follows: $125 \mathrm{NaCl}, 5.37 \mathrm{KCl}, 24 \mathrm{NaHCO}_{3}, 1$ $\mathrm{MgCl}_{2}, 1.8 \mathrm{CaCl}_{2}, 11$ glucose, $\mathrm{pH}$ 7.4) for at least $1 \mathrm{~h}$ before recording. Recordings were obtained from the left hemidiaphragm in region S2. A tight-fitting glass suction electrode was used for nerve stimulation (stimulus duration $0.1 \mathrm{~ms}$, amplitude $0.1-1 \mathrm{~V}$ ). Intracellular muscle fiber recordings were made at room temperature $\left(20^{\circ} \mathrm{C}-22^{\circ} \mathrm{C}\right)$ with $20-30 \mathrm{M} \Omega$ resistance glass microelectrodes filled with $3 \mathrm{~m}$ potassium acetate. Muscles were paralyzed with $\mu$-conotoxin ( $1 \mu \mathrm{M}$; Bachem) to block skeletal muscle but not axonal voltage-gated sodium channels. Data were acquired with custom-written MATLAB (The MathWorks) programs and digitized at $5 \mathrm{kHz}$ with DAQCard-1200 (National Instruments). Data were analyzed with Clampfit 9 (Molecular Devices) and Origin 6.1 (OriginLab). Endplate potentials (EPPs) and quantal content were corrected for nonlinear summation (McLachlan and Martin, 1981). EPPs were not corrected for extracellular field potentials sometimes generated by neighboring muscle fibers. Spontaneous activity was typically recorded for $1 \mathrm{~min}$, except for those fibers with very low spontaneous release, for which recordings were made for 2-3 min. Quantal content was calculated from the average of 50-100 EPPs at a stimulation rate of $0.5 \mathrm{~Hz}$. Because of the pulse-to-pulse variability in the EPP amplitude during trains of $20 \mathrm{~Hz}$ stimuli, the EPP amplitude during rundown experiments (data not shown) was calculated as the average of five EPPs closest to each data point (equivalent to an average response within a window duration of $200 \mathrm{~ms}$ ). Comparison of group means was performed using Student's $t$ test or one-way ANOVA with Bonferroni post hoc test.

CNS electrophysiology. Acute hippocampal slices were prepared from 9- to 12-month-old APP $\Delta$ CT15-DM mice and APLP2-KO littermate controls as previously described (Weyer et al., 2011; Hick et al., 2015). In brief, mice were anesthetized and decapitated; the brain was quickly transferred into ice-cold carbogenated $\left(95 \% \mathrm{O}_{2}, 5 \% \mathrm{CO}_{2}\right)$ ACSF for 3 min. The ACSF used for electrophysiological recordings contained 125 $\mathrm{mm} \mathrm{NaCl}, 2.5 \mathrm{~mm} \mathrm{KCl}, 1.25 \mathrm{~mm} \mathrm{NaH} \mathrm{PO}_{4}, 2 \mathrm{~mm} \mathrm{MgCl}_{2}, 26 \mathrm{~mm}$ $\mathrm{NaHCO}_{3}, 2 \mathrm{~mm} \mathrm{CaCl}_{2}$, and $25 \mathrm{~mm}$ glucose. Hippocampi were cut with a vibrating microtome (VT 1200S; Leica) into 400- $\mu$ m-thick transversal slices. Recordings were performed at $32^{\circ} \mathrm{C}$.

After placing the slices in a submerged recording chamber, field EPSPs (fEPSPs) were recorded in the stratum radiatum of the CA1 region with a glass micropipette (resistance: $3-15 \mathrm{M} \Omega$ ) filled with $3 \mathrm{M} \mathrm{NaCl}$ at a depth of $\sim 150-200 \mu \mathrm{m}$. Monopolar tungsten electrodes were used for stimulation of Schaffer collaterals at a frequency of $0.1 \mathrm{~Hz}$. Stimulation was set to elicit an fEPSP with a slope of $\sim 40 \%$ of maximum for LTP recordings. 
After 20 min of baseline stimulation, LTP was induced by applying thetaburst stimulation (TBS), in which a burst consisted of 4 pulses at $100 \mathrm{~Hz}$, which were repeated 10 times in a $200 \mathrm{~ms}$ interval $(5 \mathrm{~Hz})$. Three such trains were used to induce LTP at $0.1 \mathrm{~Hz}$. Basic synaptic transmission and presynaptic properties were analyzed via input-output (IO) measurements and paired-pulse facilitation. The IO measurements were performed by application of a defined value of current (25-250 $\mu \mathrm{A}$ in steps of $25 \mu \mathrm{A}$ ). Paired-pulse facilitation was performed by applying a pair of two stimuli spaced by different interstimulus intervals ranging from 10 , 20, 40, 80, to $160 \mathrm{~ms}$. Data were collected, stored, and analyzed with LABVIEW software (National Instruments). The initial slope of fEPSPs elicited by stimulation of the Schaffer collaterals was measured over time, normalized to baseline, and plotted as average \pm SEM. Statistical analyses were performed using Student's $t$ test.

Behavior. Behavioral analysis was performed according to the protocols previously published (Weyer et al., 2011). All behavioral procedures were approved by animal welfare authorities. A total of 34 mice of both sexes were analyzed in a blinded manner: APP $\Delta \mathrm{CT} 15, n=17$ ( 11 female, 6 male); APLP2-KO controls, $n=17$ ( 11 female, 6 male). The mice were transferred to single cages before the beginning of the experimental period and tested under dim light ( $\sim 12$ lux $)$ during the dark phase of the cycle (lights on between 8:00 P.M. and 8:00 A.M.). Standard mouse chow, water, and nesting material were available ad libitum. The home cage rack was brought to the test room at least 30 min before each experiment. Mice at the age of 5.5-7 months were analyzed over 4 weeks in the following order of tests: home cage activity, open field, grip strength, rotarod, T-maze, nesting, burrowing, and the radial maze. Criteria for postexperiment exclusions before statistical comparisons are run were technical failures, aberrant nonperformant behavior, and data values 3 SDs above mean (applies to all behavioral experiments). T-maze: one female APP $\triangle \mathrm{CT} 15-\mathrm{DM}$ was excluded as nonperformer (no choices). Radial maze: one female APLP2-KO was excluded as nonperformer (too many bait and arm neglects).

Grip strength. Forepaw grip strength was measured as described previously (Ring et al., 2007) using a Newton meter (maximum force: $300 \mathrm{~g}$ ) that was positioned horizontally and attached to a metallic ring of $5.5 \mathrm{~cm}$ diameter and $3 \mathrm{~mm}$ thickness. Mice were held by the tail and allowed to grasp the ring with both forepaws. They were then gently pulled back until they released the ring. Five measurements were obtained each on 2 consecutive days and averaged.

Home cage activity. Home cage activity was recorded as described previously (Madani et al., 2003) using a cage rack equipped with one passive IR sensor per mouse (ActiviScope, New Behavior). The sensors detected any locomotion and remained silent only when the mice were sleeping or grooming. Recording started after a habituation period of at least $18 \mathrm{~h}$, and circadian profiles were calculated by averaging data from at least 4 recording days.

Open field. Activity was tested as described previously (Madani et al., 2003). In brief, the open field was a dimly lit circular arena ( $150 \mathrm{~cm}$ diameter) in which the mice were observed and tracked using Noldus EthoVision 3.1 software (Noldus Information Technology) for 10 min each on 2 consecutive days. The arena was divided into a wall zone ( $18 \%$ of surface, $7 \mathrm{~cm}$ wide), a center zone (50\%), and a transition zone in between.

Radial maze. The working memory procedure on the 8 -arm radial maze was performed as described previously (Hick et al., 2015). The apparatus was constructed of gray polyvinyl chloride. Eight arms $(7 \times 38$ $\mathrm{cm}$ ) with clear Perspex sidewalls $(5 \mathrm{~cm}$ high) extended from an octagonal center platform (diameter: $18.5 \mathrm{~cm}$, distance between platform center and end of arm: $47 \mathrm{~cm}$ ). It was placed $38 \mathrm{~cm}$ above the floor in a dimly lit room $(4 \times 40 \mathrm{~W}$ bulbs, 12 lux) rich in salient extramaze cues (same room as for water-maze testing). Small cereal pellets $(\sim 6 \mathrm{mg})$ were placed as baits in small metal cups ( $3 \mathrm{~cm}$ diameter, $1 \mathrm{~cm}$ deep) at the end of each arm, in such a way that the mouse could not see them without completely entering the arm. A reversed box of clear Perspex served to confine the mouse on the center platform before each test session during which the mice were allowed to move freely in the maze. Mice were gradually reduced to and maintained at $85 \%$ of their free-feeding body weight using a premeasured amount of chow each day. Water was available ad libitum. Mice performed one trial per day lasting maximally $10 \mathrm{~min}$ or until the animal had collected all pellets. They began with two habituation sessions during which they were accustomed to collect pellets from the maze that were distributed all over the maze. During the following 10 training trials, each cup was baited only with one pellet. While trials were video-tracked using a Noldus EthoVision 3.1 system (www.noldus.com), consumption of each pellet was registered by pressing a designated key on the keyboard. Using this information, we calculated the number of correct choices among the first eight, as well as the number of reentry errors as a function of trial and of baits already collected.

$T$-maze. Spontaneous alternation on the T-maze was assessed as described previously (Deacon and Rawlins, 2006). The T-maze was made of gray PVC. Each arm measured $30 \times 10 \mathrm{~cm}$. A removable central partition extended from the center of the back goal wall of the $\mathrm{T}$ to $7 \mathrm{~cm}$ into the start arm. This totally prevented the mouse from seeing or smelling the nonchosen arm during the sample run, thus minimizing interfering stimuli. The entrance to each goal arm was fitted with a guillotine door. Each trial consisted of an information-gathering sample run, followed immediately by a choice run. For the sample run, a mouse was placed in the start arm, facing away from the choice point with the central partition in place. It was allowed to choose a goal arm and confined there for $30 \mathrm{~s}$ by lowering the guillotine door. Then the central partition was removed, the mouse replaced to the start arm, and the guillotine door was raised. Alternation was defined as entering the opposite arm to that entered on the sample trial (whole body, including tail). Three trials were run per day with an intertrial interval of $\sim 60$ min. Each mouse received 6 trials in total; and for data analysis, the percentage of correct choices was calculated.

Nesting test. Nest building was studied as described previously (Deacon, 2006b). At the beginning of the dark phase, mice were placed in individual testing cages (Type II, $267 \times 207 \times 140 \mathrm{~mm}$ ), containing regular bedding and a Nestlet of $3 \mathrm{~g}$ compressed cotton (Ancare). After $24 \mathrm{~h}$, the nests were assessed on a rating scale of $1-5: 1=$ Nestlet $>90 \%$ intact; 2 = Nestlet $50-90 \%$ intact; $3=$ Nestlet mostly shredded but no identifiable nest site; $4=$ identifiable but flat nest; $5=$ crater-shaped nest.

Burrowing test. Burrowing was studied as described previously (Deacon, 2006a). A gray plastic tube (inner diameter: $6.3 \mathrm{~cm}$; length: $18.2 \mathrm{~cm}$ ) was filled with $350 \mathrm{~g}$ standard diet food pellets (Kliba Nafag 3430, Provimi Kliba; $\sim 3 \mathrm{~g}$ each) and placed at a slight angle into a large standard transparent mouse cage (Type III, $425 \times 266 \times 155 \mathrm{~mm}$ ). The lower end of the tube was closed, resting on the cage floor. The open end was supported $3.5 \mathrm{~cm}$ above the floor by two metal bolts. The cage floor was covered with fresh standard bedding material, and a cardboard environmental enrichment tube was also placed in the test cage. At the beginning of the dark period, mice were placed individually in test cages and left in their familiar animal room for an observation period of $4 \mathrm{~h}$ after which the amount of nondisplaced food was measured. This was followed by a second observation period of $20 \mathrm{~h}$. Water was available ad libitum during the entire period. It was assumed that the amount of food eaten per mouse $(2 \pm 0.5 \mathrm{~g})$ was a very small portion of the $350 \mathrm{~g}$ available and approximately equal across the groups.

Data were analyzed using mixed ANOVA models with genotype (APP $\Delta$ CT15-DM, APLP2-KO control) as between-subject factor and within-subject factors to explore the dependence of genotype effects on place, time, or response type. Sex factor is not reported because there were no genotype $X$ sex interactions. Significant interactions and, where necessary, significant main effects were further explored by TukeyKramer's post hoc tests or by splitting the ANOVA model, as appropriate. One-sample $t$ tests were used for follow-up comparisons against chance levels. Variables known to produce strongly skewed distributions and/or frequent outliers were subjected to a $\log (1+x)$ transformation before ANOVA as indicated. The significance threshold was set at $p=0.05$. The false discovery rate control procedure of Hochberg was applied to groups of conceptually related variables within single tests to correct significance thresholds for multiple comparisons.

\section{Results}

APP $\Delta C T 15$ only partially rescues the postnatal lethality of APP/APLP2 double knock-out mice

To assess in more detail the specific role of the APP C-terminus for early postnatal development and in the adult CNS, we crossed 


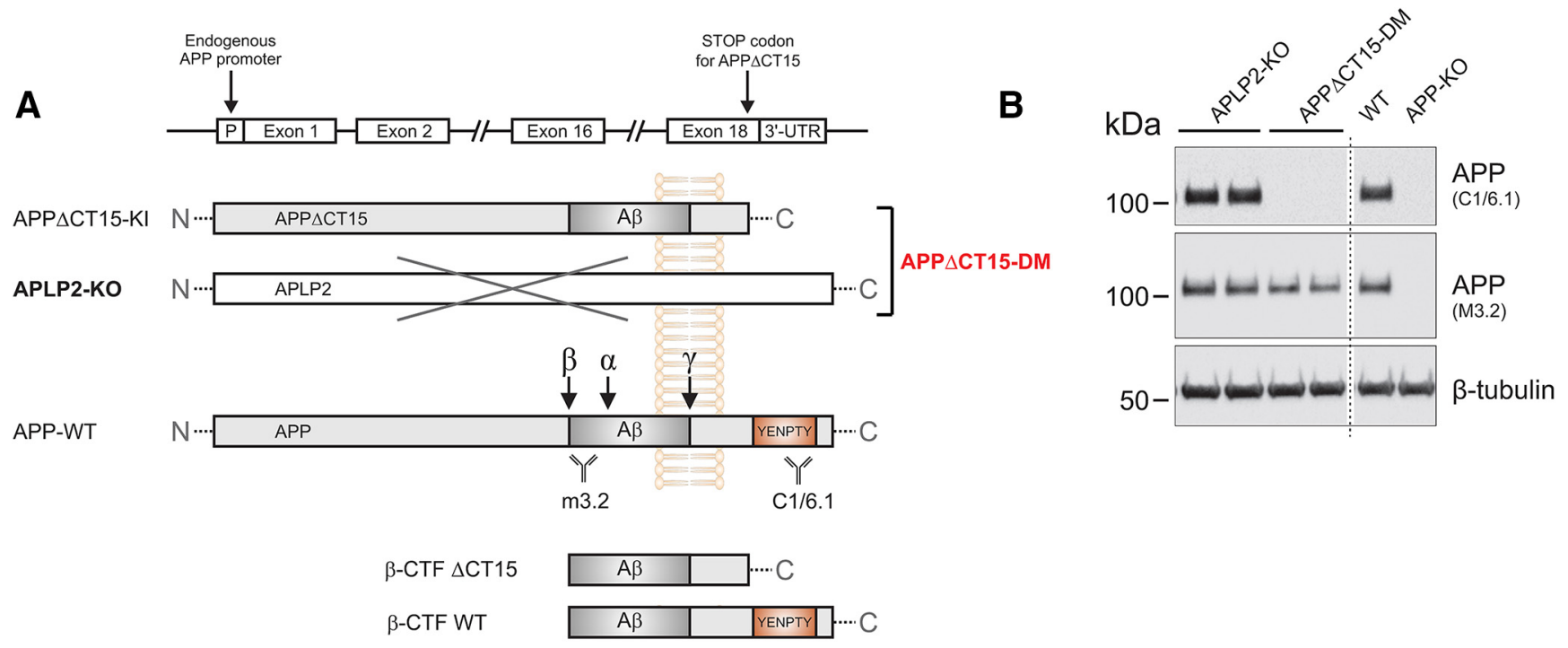

C
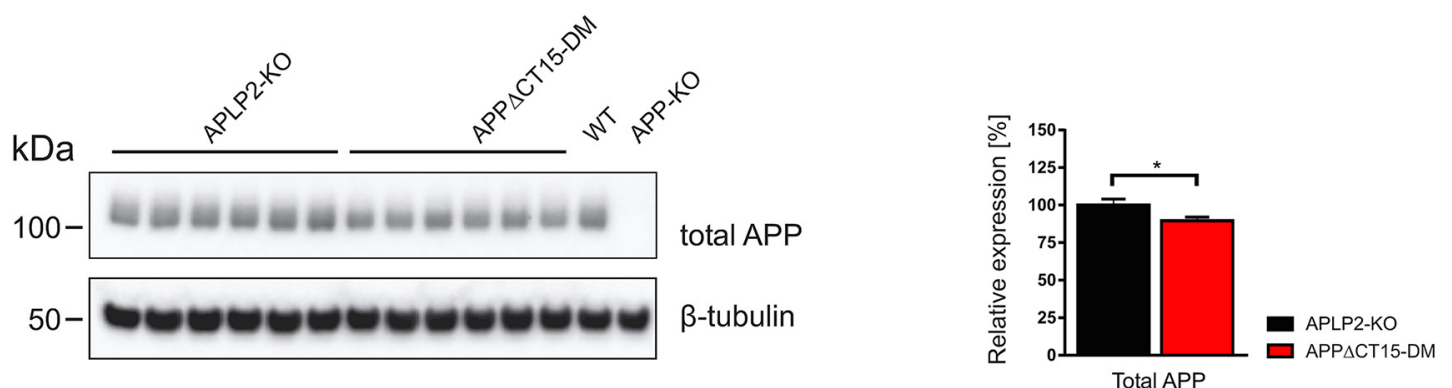

D
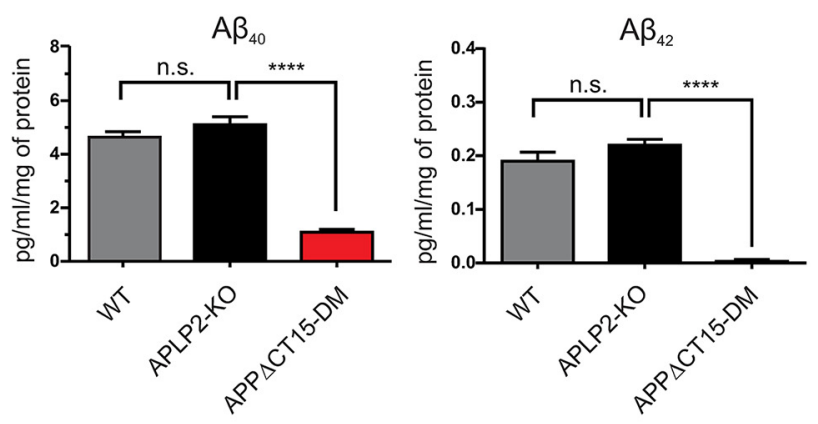

$\mathbf{F}$

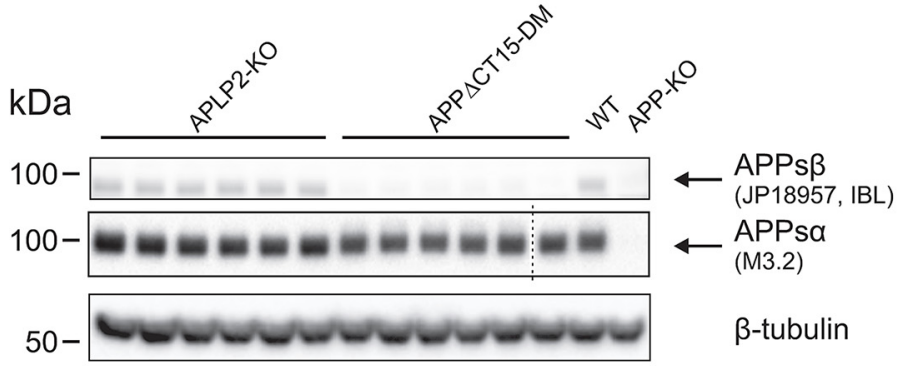

E

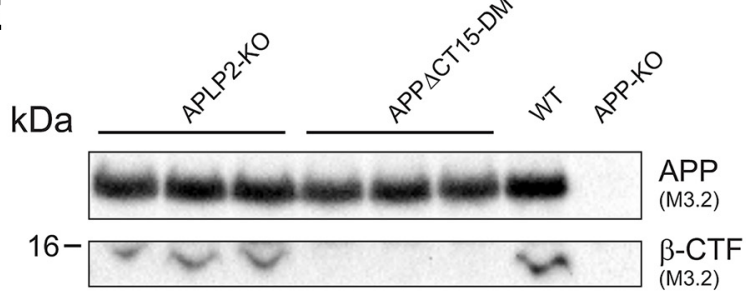

Figure 1. Analysis of APP processing in APP $\Delta$ CT15-DM mice. $A$, Scheme depicting APP, WT, and APP $\triangle C$ C15 truncation. A stop codon was inserted into APP exon 18 leading to the deletion of the last 15 amino acids, including the YENPTY interaction motif. The APP $\Delta$ CT15 variant is expressed under the control of the endogenous APP promoter. APP $\Delta$ CT15-DM mice were generated by crossing APP $\Delta$ CT15 knockin (KI) mice with APLP2-K0 mice; for final heterozygous intercrosses, APP ${ }^{\Delta /+}$ APLP2-K0 mice were used. APLP2-K0 mice served as internal littermate controls. $B$, Expression of APP and antibody specificity was analyzed in brain homogenates from APLP2-KO littermate controls, APP $\triangle C T 15-D M$, WT, and APP-K0 mice. No signal is detected using C1/6.1 antibody directed against the APP (-terminus (top; for antibody epitopes, see $\boldsymbol{A}$ ). M3.2 antibody detects both APP-WT and APP $\Delta$ CT15, whereas no signal is obtained in APP-K0 brain. $\beta$-tubulin staining served as a loading control. C, Western blot of total APP (M3.2 antibody) in adult mouse brain homogenates (left). Quantification (right) showed slightly reduced total APP levels (Figure legend continues.) 
Table 1. Genotype distribution and survival of APP $\Delta C T 15-D M$ and APP/APLP2-DKO mice at weaning

\begin{tabular}{|c|c|c|c|c|c|}
\hline Matings (genetic background) & Genotype (expected frequency) & Total offspring & Obtained (frequency) & Obtained of expected & $\chi^{2}$ test \\
\hline $\mathrm{APP}^{+/ \Delta} \mathrm{APLP}^{-/-}(\mathrm{R} 1)$ & $\begin{array}{l}\mathrm{APP}^{\Delta / \Delta} \mathrm{APLP}^{-/-}(25 \%) \\
\mathrm{APP}^{+/ \Delta} \mathrm{APLP}^{-/-}(50 \%) \\
\mathrm{APP}^{+/+} \mathrm{APLP2}^{-/-}(25 \%)\end{array}$ & 583 & $\begin{array}{r}66(11.3 \%) \\
329(56.4 \%) \\
188(32.2 \%)\end{array}$ & $45.3 \%$ & 7 \\
\hline $\mathrm{APP}^{+/-} \mathrm{APLP}^{-/-}(\mathrm{R} 1)$ & $\begin{array}{l}\mathrm{APP}^{-/-} \mathrm{APLP2}^{-1-}(25 \%) \\
\mathrm{APP}^{+/-} \mathrm{APLP2}^{-1-}(50 \%) \\
\mathrm{APP}^{+/+} \mathrm{APLP2}^{-1-}(25 \%)\end{array}$ & 813 & $\begin{array}{c}39(4.8 \%) \\
467(57.4 \%) \\
307(37.8 \%)\end{array}$ & $19.2 \%$ & \rfloor \\
\hline $\mathrm{APP}^{+/ \Delta} \mathrm{APLP}^{-/-}(\mathrm{R} 6)$ & $\begin{array}{l}\mathrm{APP}^{\Delta / \Delta} \mathrm{APLP}^{-/-}(25 \%) \\
\mathrm{APP}^{+/ \Delta} \mathrm{APLP}^{-/-}(50 \%) \\
\mathrm{APP}^{+/+} \mathrm{APLP2}^{-/-}(25 \%)\end{array}$ & 1189 & $\begin{array}{c}80(6.7 \%) \\
699(58.8 \%) \\
410(34.5 \%)\end{array}$ & $26.9 \%$ & \\
\hline $\mathrm{APP}^{+/-} \mathrm{APLP}^{-/-}(\mathrm{R} 6)$ & $\begin{array}{l}\mathrm{APP}^{-/-} \mathrm{APLP2}^{-/-}(25 \%) \\
\mathrm{APP}^{+/-} \mathrm{APLP}^{-/-}(50 \%) \\
\mathrm{APP}^{+/+} \mathrm{APLP2}^{-1-}(25 \%)\end{array}$ & 798 & $\begin{array}{c}14(1.8 \%) \\
485(60.8 \%) \\
299(37.5 \%)\end{array}$ & $7 \%$ & \\
\hline
\end{tabular}

APP $\triangle$ CT15-DM and APP/APLP2-DK0 mice were obtained from heterozygous APP ${ }^{+/ \Delta} \mathrm{APLP}^{-/-}$and APP ${ }^{+/-} \mathrm{APLP}^{-/-}$intercrosses. The survival rate of mutant mice varied depending on the genetic background. Mice with a mixed genetic background $(\mathrm{R} 1=129 / 0 \mathrm{la} \times(57 \mathrm{BL} / 6)$ showed a higher survival rate than mice backcrossed at least 6 times to $\mathrm{C57BL} / 6$ (R6). Depending on the genetic background, $\sim 27 \%$ (R6) to $\sim 45 \%$ (R1) of expected APP $\Delta$ CT15-DM mice were obtained at weaning (P21-P28), whereas only 7\% (R6) to 19\% (R1) of APP/APLP2-DK0 mice were viable. Statistical significance was calculated using $\chi^{2}$ test with regard to the expected Mendelian genotype distribution (*** $p<$ 0.001 ) for each of the given matings; data not shown) or between the different genotypes.

APP $\Delta$ CT15-KI mice lacking the last 15 amino acids of APP with APLP2-deficient mice. Double mutants (designated APP $\Delta$ CT15$\mathrm{DM}$ ) were obtained from heterozygous $\mathrm{APP}{ }^{\Delta /+} \mathrm{APLP}^{-/-}$intercrosses (Fig. 1A; Table 1). For comparison, DKOs were generated in parallel by intercrossing heterozygous $\mathrm{APP}^{-1+} \mathrm{APLP}^{-/-}$ mice (Table 1). As the genetic background may influence the penetrance and severity of knock-out phenotypes (Wolfer and Lipp, 2000; Aydin et al., 2011), we also investigated whether the genetic background may affect survival rates. To this end, we compared genotype distributions in animals of mixed genetic background $(129 / \mathrm{OLA} \times \mathrm{C} 57 \mathrm{BL} / 6)$ that had been backcrossed only once to C57BL/6 (designated R1) and animals backcrossed to C57BL/6 for $>6$ generations (designated R6; Table 1). Newborn homozygous APP $\Delta$ CT15-DMs showed a Mendelian-like genotype distribution ( $\chi^{2}$ test, $p=0.238, \mathrm{R} 1$ background, $n=$ 244 newborns) similarly as previously shown for APP/APLP2DKO mice (von Koch et al., 1997; Heber et al., 2000), thus excluding prenatal lethality. At weaning, we obtained a considerable proportion of surviving homozygous APP $\Delta$ CT15-DM mice, however, significantly $\left(\chi^{2}\right.$ test, $\left.p<0.001\right)$ less than expected from Mendelian frequency: $\sim 45.3 \%$ of expected homozygous APP $\Delta$ CT15-DM mice survived on mixed (R1) background ( 66 of 583 total offspring), whereas we found a lower survival rate of $26.9 \%$ of expected (80 of 1189 total offspring) on backcrossed C57BL/6 (R6) background (Table 1). Earlier studies reported a small number of surviving APP/APLP2-DKO "escape" mutants (von Koch et al., 1997; Heber et al., 2000). Here, we analyzed

\footnotetext{
(Figure legend continued.) in APP $\triangle$ CT15-DM mice ( $~ 89.6 \%$ of APLP2-K0 set as $100 \%)$. D, $A \beta_{40}$ and $A \beta_{42}$ were quantified by ELISA. $A \beta_{40}$ and $A \beta_{42}$ levels were similar in APLP2-KO and WT mice. In contrast, $A \beta_{40}$ and $A \beta_{42}$ were severely reduced in APP $\triangle C T 15-D M$ mice. $A \beta_{40}$ : ANOVA, $F_{(2,14)}=99,37 ; p<0.0001$ with Tukey's post hoc test; $A \beta_{42}: A N O V A, F_{(2,14)}=119.3$; $p<0.0001$ with Tukey's post hoc test; WT, $n=5 ; \mathrm{APLP2}-\mathrm{K} 0, n=6 ; \mathrm{APP} \Delta \mathrm{CT15}-\mathrm{DM}, n=6 . \boldsymbol{E}$, $\beta$-CTF is detected in membrane fractions obtained from cortices of adult APLP2-KO littermate and WT mice using antibody M3.2 directed against the $\mathrm{N}$-terminus of the A $\beta$-region. № $\beta$-CTFs were detectable in APP $\triangle$ CT15-DM mice or APP-K0 mice that served as a negative control. Short exposure of the same gel is shown for detection of full-length APP (top), long exposure (bottom) for $\beta$-CTF detection. $\boldsymbol{F}$, Analysis of soluble APP fragments indicated highly reduced APPs $\beta$ (14.4\% of APLP2 control mice) but only nonsignificant, minor reduction of APPs $\alpha$ (93.2\%). Dotted line indicates that samples were run on the same gel but not in adjacent lanes. $\boldsymbol{C}, \boldsymbol{F}$, APLP2-KO, $n=6 ;$ APP $\Delta$ CT15-DM, $n=6$. Values are mean \pm SEM. ${ }^{* * *} p<0.0001$ ( $t$ test). ${ }^{* *} p<0.01$ ( $t$ test). ${ }^{*} p<0.05$ ( $t$ test). n.S., Not significant.
}

survival more systematically in a large set of offspring (cumulating data over several years) and found that either $19.2 \%$ of the expected DKOs (R1) or only 7\% of backcrossed DKOs (R6) survived (Table 1). Importantly, however, for both genetic backgrounds (R1 and R6), the percentage of surviving APP $\Delta$ CT15-DM mice was significantly and considerably higher $(\sim 2.3$ - to 3.8 -fold $)$ than the percentage of viable DKO animals ( $\chi^{2}$ test, $p<0.001$; Table 1$)$. Together, these data clearly indicate that the APP $\Delta$ CT15 allele is able to only partially rescue the lethality of DKO mutants and that genetic background modulates postnatal survival rates of APP/APLP mutants. To avoid potentially confounding effects of background alleles, the subsequent phenotypic analysis of surviving adult APP $\Delta$ CT15-DM mice was performed in backcrossed (R6) animals.

\section{Lack of the APP C-terminus impairs A $\beta$ generation in APP $\Delta$ CT15-DM mice}

We then investigated the role of the APP C-terminus for endogenous APP processing in vivo (Fig. 1). As a baseline for further experiments, we confirmed the lack of the APP C-terminus in APP $\Delta$ CT15-DM mice by Western blot analysis (Fig. $1 A, B$ ) using a C-terminus specific antibody $(\mathrm{C} 1 / 6.1)$ and $\mathrm{APP}-\mathrm{KO}$ mice as a negative control. Expression of total APP $\Delta$ CT15 was slightly reduced $(89.6 \%$ of control, $p=0.0411$; Fig. $1 C)$ due to somewhat reduced expression at the mRNA level in KI mice (Ring et al., 2007). Previously, we had shown in APP $\Delta$ CT15-KI single mutants (Ring et al., 2007) that lack of the APP-CT15 domain, which contains the YENPTY consensus motif for clathrin-mediated endocytosis, enhances APP cell surface expression and reduces cellular APP turnover, likely via reducing endosomal $\beta / \gamma$-secretase processing (Perez et al., 1999). Consistent with our previous analysis of APP mutants (Ring et al., 2007), A $\beta 40$ levels (determined by a sensitive electrochemiluminescence ELISA) were highly reduced (to $\sim 21.3 \pm 2.2 \%$ of littermate control levels; Fig. $1 D$ ) in cortical brain lysates of APP $\Delta$ CT15-DM mice. Similarly, while $\mathrm{A} \beta 42$ was readily detectable in littermate controls, $A \beta 42$ levels were close to the detection limit in APP $\Delta$ CT15-DM brain (Fig. $1 D)$. Likewise, although we could detect $\beta$-CTFs ( $\beta$-secretase generated $\mathrm{C}$-terminal fragments) in membrane-enriched fractions of wild-type mice and littermate controls, we failed to detect them in APP $\triangle$ CT15-DM mice (Fig. 1E). Next, we assessed whether lack of the APP-CT15 domain affects APPs ectodomain shedding (Fig. $1 F$ ). Consistent with reduced $\mathrm{A} \beta$ and $\beta$-CTF levels, we detected also a pronounced reduction of soluble APPs $\beta$ 
(to $14.4 \%$ of control, $p=0.0022$, Student's $t$ test; Fig. $1 F$ ), whereas APPs $\alpha$ levels (93.2\% of control; $p=0.2381$, Student's $t$ test) were not significantly different in APP $\Delta$ CT15-DM mice. Together, these data indicate that lack of the APP-CT15 domain in APP $\triangle$ CT15-DM mice strongly impairs amyloidogenic APP processing in vivo, whereas APPs $\alpha$ levels are similar to littermate controls.

\section{APP $\Delta$ CT15-DM mice exhibit a widened endplate band with smaller and fragmented neuromuscular synapses}

Previously, aberrant neuromuscular synaptic morphology was found in newborn lethal APP/APLP2-DKO mice (Wang et al., 2005; Klevanski et al., 2014) and also in adult APPs $\alpha$-DM mice lacking transmembrane APP and expressing solely APPs $\alpha$ (Weyer et al., 2011). To investigate whether the APP-CT15 domain is required for proper neuromuscular junction (NMJ) morphology, we studied the diaphragm from surviving young adult APP $\Delta$ CT15-DMs compared with APLP2-KO littermates and WT controls (Fig. 2). Endplate topology was visualized by bungarotoxin rhodamine staining of AChRs. In adult (2-month-old) APP $\Delta$ CT15-DM mice, endplates were distributed over a much larger muscle area (Fig. 2A), although the size of the diaphragm along the left-right body axis was not altered in mutant mice (Fig. 2B). Quantification of synapse distribution also showed a significant increase of endplate band width (Fig. $2 C$ ) and a concomitant reduction in synapse density with no change in the total synapse number (Fig. 2D,E). To assess the severity of endplate widening, we also studied diaphragms of newborn APP $\Delta$ CT15-DM compared with lethal DKO mice (Fig. $2 F-J$ ). The synapse band widths of newborn APP $\Delta$ CT15-DM and DKO mice were significantly increased to a similar extent compared with controls (Fig. $2 \mathrm{~F}, H-J$ ). This was also associated with a similar degree of nerve terminal sprouting in mice of both genotypes (Fig. 2G). Next, we studied the morphology of individual synapses at high magnification (Fig. 3). In adult surviving APP $\Delta$ CT15-DM mice, we found that both the postsynaptic area covered by AChRs and the size of synaptophysinimmunoreactive presynaptic specializations were significantly reduced compared with APLP2 and WT controls (Fig. 3A-C). Interestingly, we also noted a gradual, significant reduction already in APLP2-KO single mutants compared with WT (Fig. $3 A-C)$. In addition, many endplates of APP $\Delta$ CT15-DM mice appeared fragmented, consisting of several small discontinuous islands contrasting with the typical "pretzel"-like pattern found in adult WT mice (Fig. 3A). Computer-assisted quantification confirmed a highly increased degree of fragmentation in APP $\triangle$ CT15-DM mice (Fig. 3D). Again, we asked whether the phenotype might be similar or ameliorated in APP $\Delta$ CT15-DM mice compared with completely APP/ APLP2-deficient DKOs. Analysis of newborn mice (Fig. $3 E-H)$ indicated significantly reduced presynaptic and postsynaptic area in both APP $\Delta$ CT $15-D M$ and DKO mutants (Fig. $3 F, G)$, with a slightly more pronounced reduction in DKO mice that did, however, not reach statistical significance. In addition, presynaptic and postsynaptic apposition was found to be significantly reduced to a similar extent in synapses of APP $\Delta$ CT15-DM and DKO pups, as evidenced by Manders' overlap coefficients (Fig. $3 H$ ). These data indicate that, although a proportion of APP $\Delta$ CT15-DM mice survive up to weaning, NMJ morphology is compromised and closely resembles that of lethal DKO mice, suggesting a crucial role of the last 15 amino acids for NMJ formation and maintenance.

\section{Impaired neuromuscular transmission and motor} performance in surviving APP $\Delta$ CT15-DM mice

Next, we examined whether impaired neuromuscular morphology is associated with functional deficits. APP and APLPs have been localized to presynaptic and postsynaptic compartments at the NMJ (Wang et al., 2005; Klevanski et al., 2014) and in the CNS to the presynaptic active zone (Laßek et al., 2013). Moreover, biochemical studies had indicated that APP binds via the YENPTY motif to several adaptors, including Fe65 and Mint proteins that, in turn, bind to Munc18 and may thus link APP to the vesicle release machinery (Weyer et al., 2011). Spontaneous transmitter release recorded from the diaphragm was, however, not affected in adult APP $\Delta$ CT15-DM mice, as evidenced by lack of significant differences in miniature endplate potential (MEPP) frequency or amplitudes (Fig. $4 A, B$ ). We also studied potential differences in evoked transmitter release. Although quantal content (e.g., the response to a single action potential) was unaffected (Fig. 4C), APP $\Delta$ CT15-DM mice revealed a significantly reduced readily releasable pool (Fig. $4 D$ ) determined according to Elmqvist and Quastel (1965), which implies a reduction in the number of presynaptic release sites and is consistent with the decrease in presynaptic area shown in Figure 3. The probability of synaptic vesicle release was increased (Fig. $4 E$ ), which may explain why the quantal content was unchanged (Fig. $4 C$; quantal content is the product of the readily releasable pool and the probability of release). Short-term plasticity was studied by measuring paired-pulse facilitation and was normal (data not shown). Notably, when stimulating the phrenic nerve for $10 \mathrm{~s}$ with $20 \mathrm{~Hz}$ trains of action potentials, APP $\Delta$ CT15-DM mice displayed significant deficits to sustain transmitter release over prolonged periods of stimulation (Fig. $4 F$ ). Consistent with these findings, we observed a pronounced grip strength deficit in APP $\Delta$ CT15-DM mice (Fig. 4G). As a baseline for subsequent cognitive tests, we studied spontaneous locomotor activity in a familiar home cage where APP $\Delta$ CT15-DM mice showed increased activity (Fig. $4 H$ ). In the open field that assesses locomotor and exploratory behavior in a novel environment, APP $\Delta$ CT15-DMs displayed increased locomotion and lacked habituation observed in APLP2-KO littermate controls (Fig. 4I). In addition, APP $\Delta$ CT15-DMs showed significantly reduced avoidance of the center field (Fig. $4 J$ ). This, together with the highly abnormal time course of activity in the home cage and the open field, is likely related to hippocampal dysfunction (see also below). Together, our data indicate that, whereas APP $\Delta$ CT15-DM mice show deficits in demanding motor tasks involving sustained muscle contraction, basal locomotion is not impaired.

\section{Impaired synaptic plasticity and hippocampus-dependent behavior}

As we have previously shown an impairment in synaptic plasticity in aged APP-KO mice, we explored whether lack of the APP-CT15 domain may affect LTP. LTP induction by TBS led to an overall increase in synaptic strength in both APP $\Delta$ CT15-DMs and APLP2-KO littermate controls (Fig. 5A). APP $\Delta$ CT15-DMs revealed significantly decreased potentiation already at early time points after TBS during the induction phase of post tetanic potentiation (Fig. 5A). This defect proceeded into the maintenance phase of the LTP, showing a significant reduction of average potentiation at 55-60 min after TBS of $129 \pm 6.0 \%(n=15 / 4$ corresponding to 15 slices from 4 mice) for APP $\Delta$ CT15-DM mice compared with $160 \pm 9.7 \%(n=16 / 5)$ for littermate controls (Fig. $5 B ; p=0.015, t$ test). To assess whether this defect persists also at later phases of protein synthesis-dependent LTP (termed late-LTP), responses were recorded $3 \mathrm{~h}$ after TBS, and the mean 
A

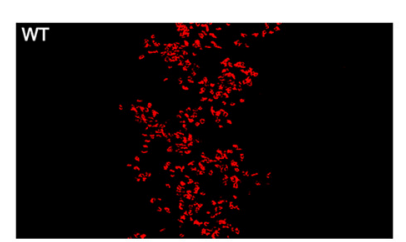

B
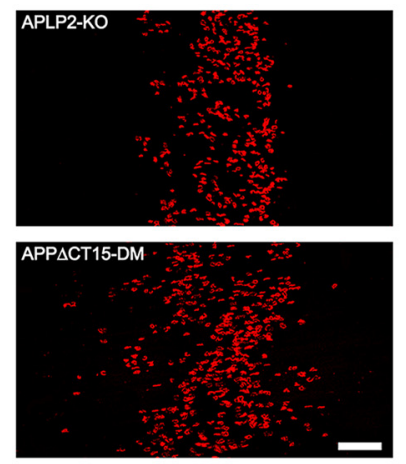

F
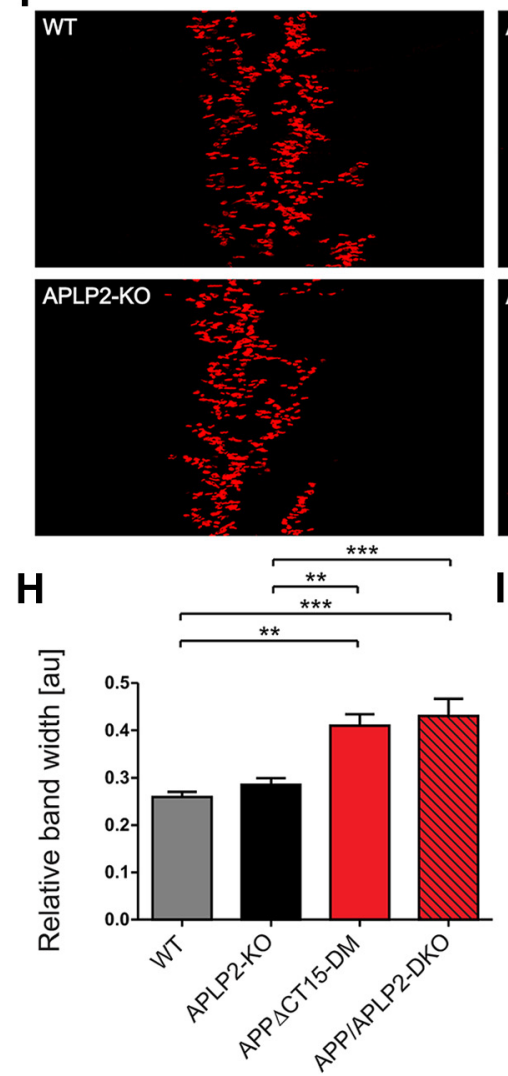
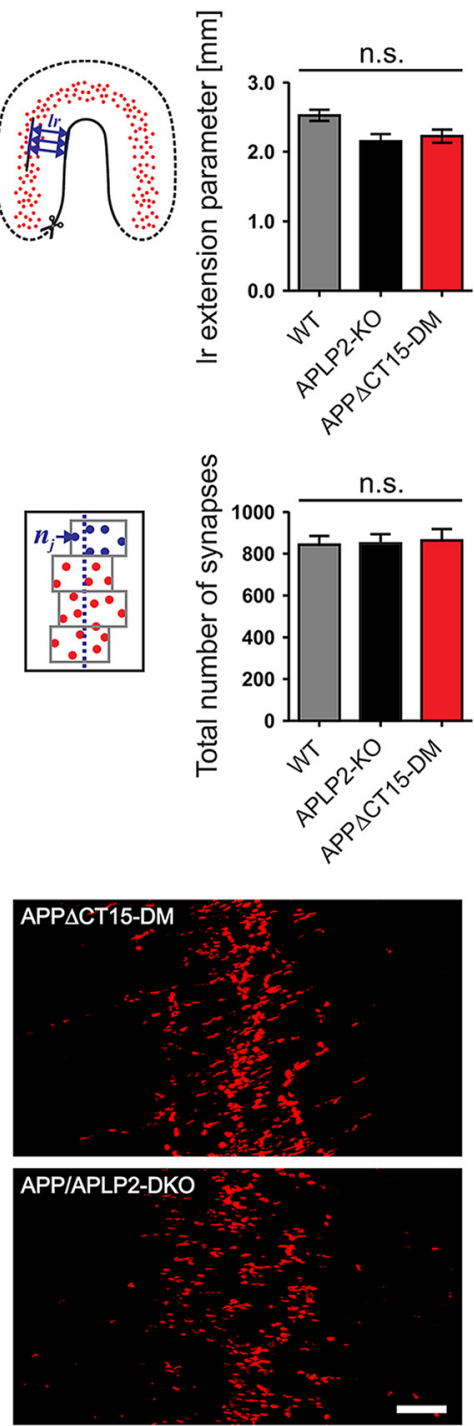

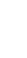

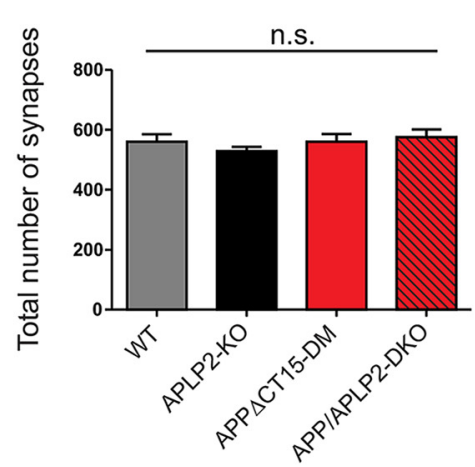

C

E
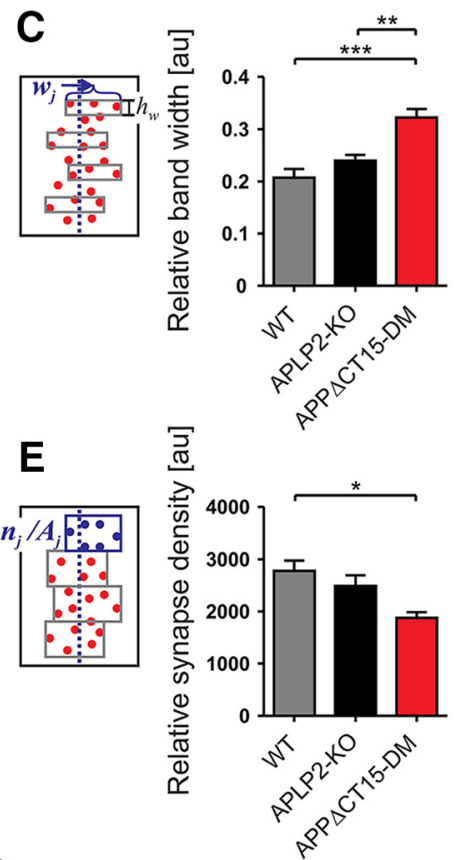

G
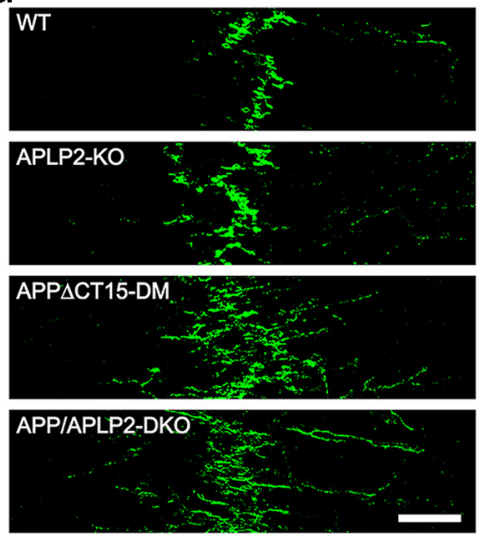

J

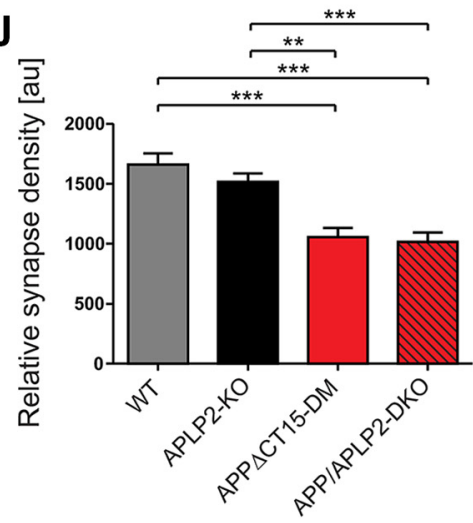

Figure 2. Widening of the endplate band and excessive branching of the phrenic nerve in APP $\Delta$ CT15-DM mice. A, Representative images of whole-mount bungarotoxin staining of diaphragm muscles from adult (2-month-old) mice. $\boldsymbol{B}$, Left-right (Ir) extension of the diaphragm was measured as distance of synapse band from muscle border. The Ir extension was not altered in mutant mice. $\boldsymbol{C}-\boldsymbol{E}$, Quantitative analysis of endplate distribution. $\boldsymbol{C}$, The width $(w)$ of the synapse band was calculated from 8 equidistantly positioned endplate-containing segments. Note the widening of the endplate band in adult APP $\triangle(T 15-D M$ mice. $\boldsymbol{D}$, Total synapse numbers $(n)$ quantified from 8 band subareas are unaffected among all genotypes analyzed. $\boldsymbol{E}$, Synapse density calculated as synapse number (shown in $\boldsymbol{C}$ per subarea $(\boldsymbol{n} / \mathrm{A}$ ) is significantly reduced in APP $\Delta$ CT15-DM adult mice compared with WT. $\boldsymbol{F}-\boldsymbol{J}$, Analysis of endplate distribution in newborn (P0) mice. $\boldsymbol{F}$, Whole-mount bungarotoxin staining revealed widening of the endplate band already in newborn APP $\triangle$ CT15-DMs to an extent similar to newborn APP/APLP2-DKO mice. G, Exemplary panels demonstrating excessive nerve terminal branching, visualized by synaptophysin immunostaining (green), in both APP $\Delta$ CT15-DM and APP/APLP2-DK0 newborns. Quantification of synapse band parameters reveals that both APP $\triangle$ CT15-DM and APP/APLP2-DKO PO mice exhibit a significantly increased synapse band width $(\boldsymbol{H})$ accompanied by a reduced synapse density $(\boldsymbol{J})$ while the total number of synapses per comparable area was equal for the genotypes analyzed ( $\boldsymbol{I}$ ). Number of mice analyzed in $(-\boldsymbol{E}$ (age: 2 months): WT, $n=5 ;$ APLP2-KO, $n=7$; APP $\Delta$ CT15-DM, $n=4$; in $H-J$ (age: P0): WT, $n=5 ;$ APLP2-K0, $n=8 ;$ APP $\Delta C$ CT15-DM, $n=5 ;$ APP/APLP2-DK0, $n=5$. Error bars indicate mean \pm SEM. One-way ANOVA with Bonferroni post hoc test: ${ }^{* * *} p<0.001,{ }^{* *} p<0.01,{ }^{*} p<$ 0.05 , n.S., not significant. Scale bars: $A, \boldsymbol{F}, 100 \mu \mathrm{m} ; \boldsymbol{G}, 200 \mu \mathrm{m}$. 
A

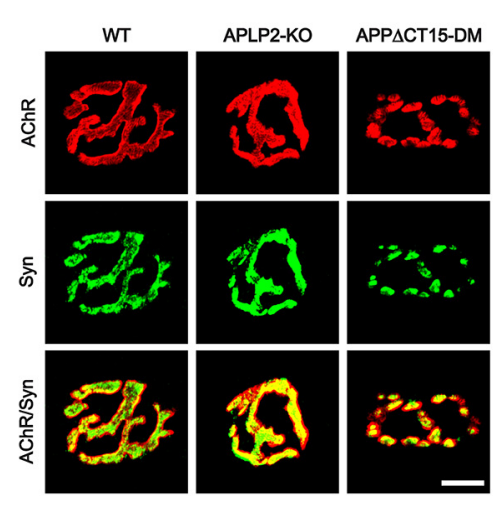

D

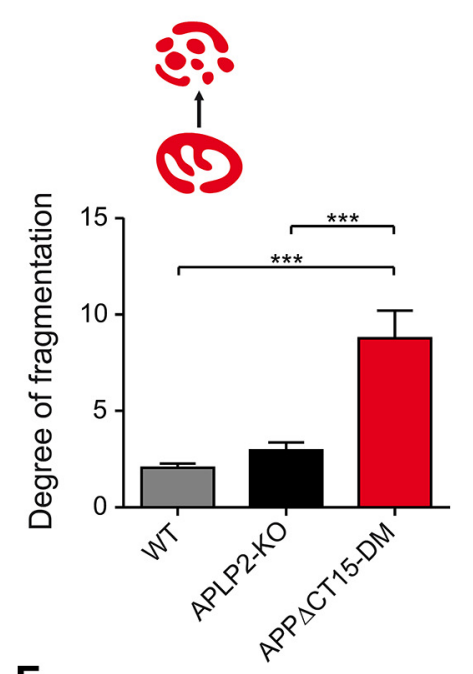

$\mathbf{F}$

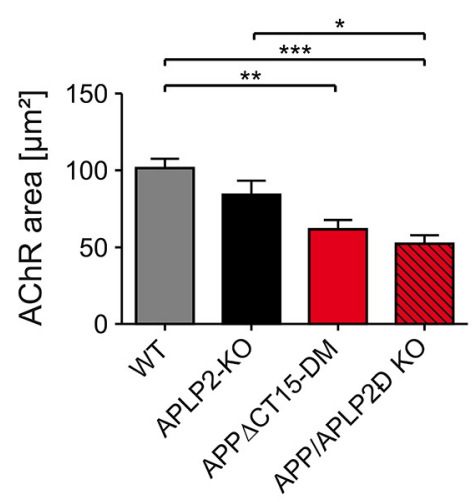

B

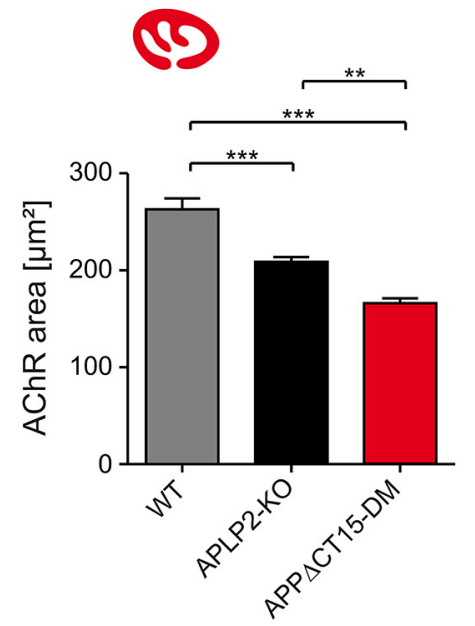

E
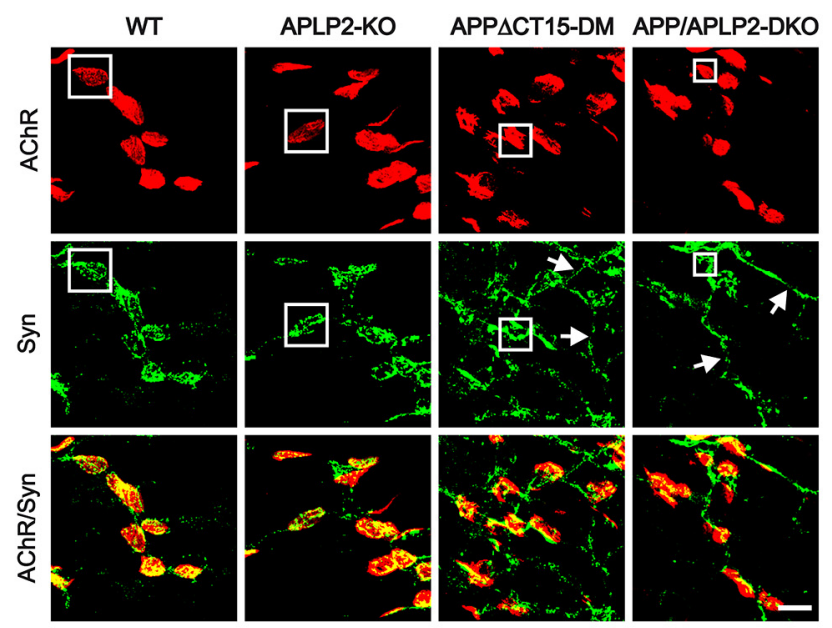

G

H

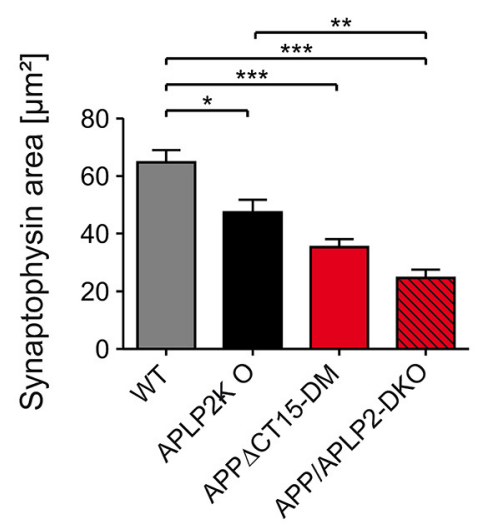

C

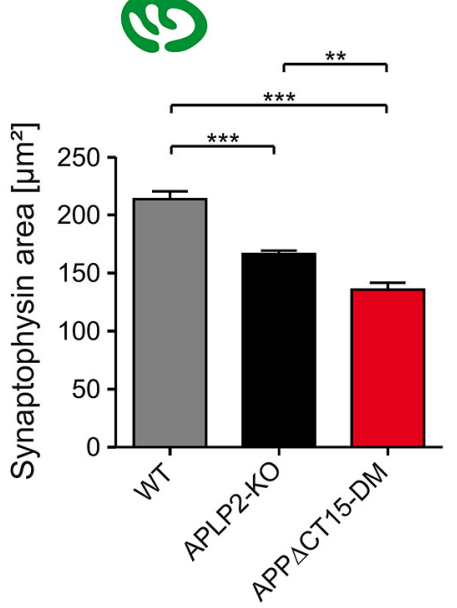

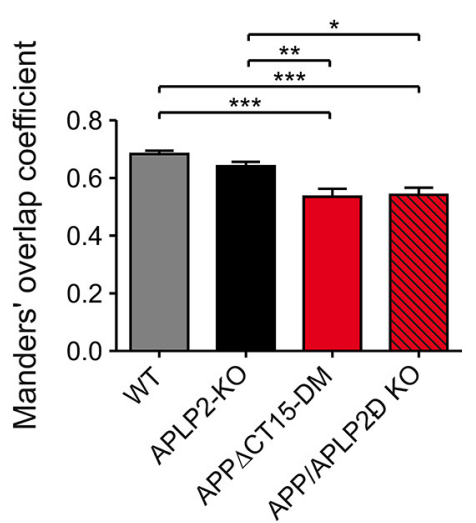

Figure 3. APP $\Delta C T 15-D M$ mice show abnormal synaptic morphologies and deficits in presynaptic/postsynaptic apposition. A, Synaptic morphology of adult mice. Postsynaptic AChRs were labeled by bungarotoxin (red), presynaptic specializations by synaptophysin staining (Syn, green). Quantitative analysis indicates a significant reduction of both the area covered by AChRs ( $\boldsymbol{B}$ ) as well as the synaptophysin-occupied area $(\boldsymbol{C})$ in APP $\Delta$ CT15-DM mice. Representative images of bungarotoxin-stained AChR clusters $($ see $\boldsymbol{A}$ ) and computer-based quantification (D) reveal that endplates of adult APP $\Delta$ CT15-DM mice appear fragmented, consisting of a significantly increased number of islands, whereas WT synapses show a typical pretzel-like shape. $\boldsymbol{E}, \boldsymbol{F}$, Morphological NMJ abnormalities in newborn APP $\triangle$ CT15-DM mice are similar to those observed in APP/APLP2-DKOs. $E$, White boxes highlight presynaptic and postsynaptic specializations. Arrows indicate nerve terminal overgrowth in APP $\Delta$ CT15-DM and APP/APLP2-DK0 animals. Quantification reveals significantly reduced areas of presynapses $(\boldsymbol{F})$ and postsynapses (G) in both newborn APP $\Delta C$ CT15-DM

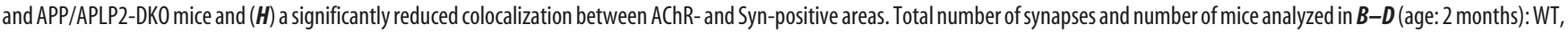
$n=213 / 5$ (corresponding to 213 synapses from 5 mice); APLP2-K0, $n=218 / 6$; APP $\Delta$ CT15-DM, $n=106 / 4$; in $\boldsymbol{F}-\boldsymbol{H}$ (age: P0): WT, $n=119 / 6 ;$ APLP2-KO, $n=80 / 5 ;$ APP $\Delta$ CT15-DM, $n=75 / 4$; APP/APLP2-DKO, $n=75 / 4$. Bars represent mean \pm SEM. One-way ANOVA with Bonferroni post hoc test: ${ }^{* *} p<0.001,{ }^{* *} p<0.01,{ }^{*} p<0.05$. Scale bars: $\boldsymbol{D}, 10 \mu \mathrm{m} ; \boldsymbol{E}, 15 \mu \mathrm{m}$. 
A
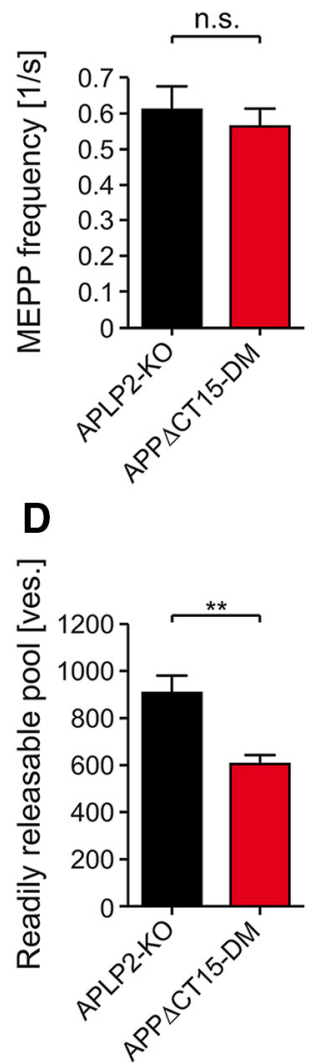

G

Grip strength

genotype

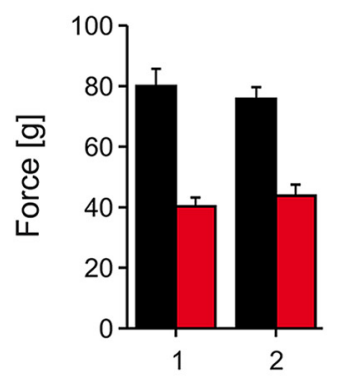

Session
B

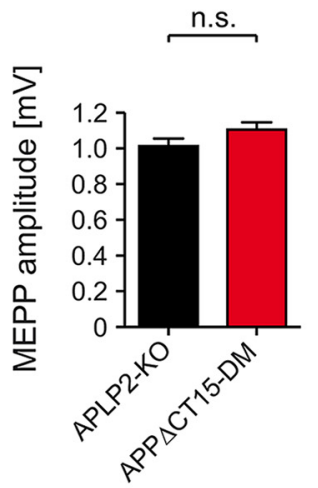

E

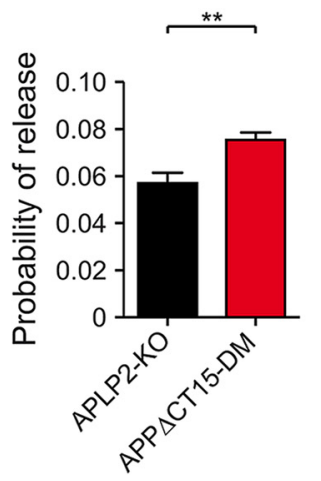

H

Home cage activity

phase $\times$ genotype $P<0.0003$

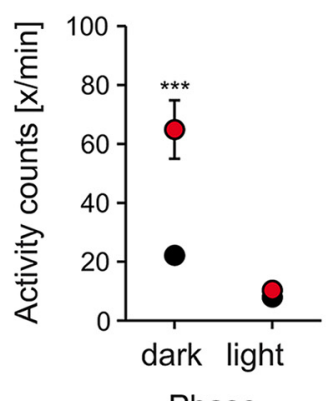

Phase
C

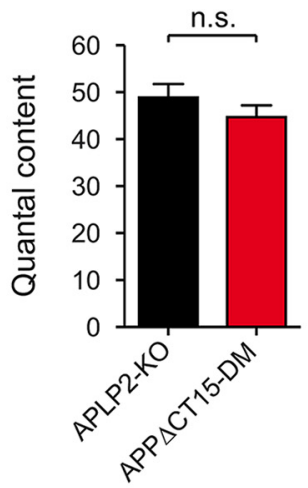

F

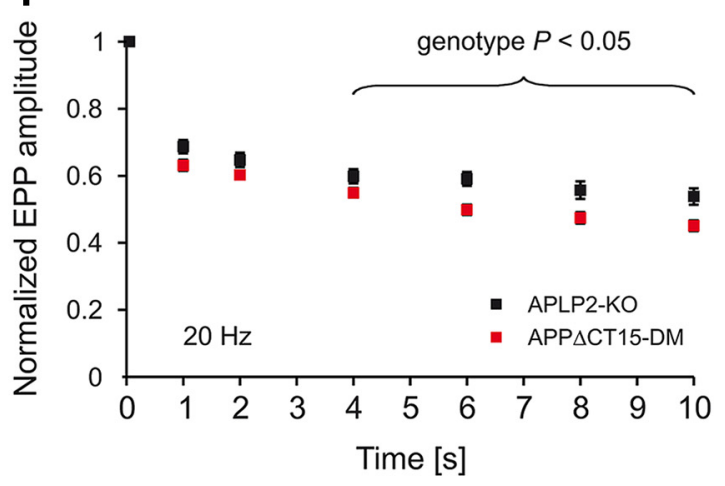

I

\section{Open field}

J

time $\times$ genotype

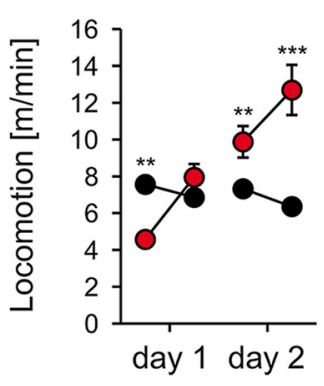

(5 min bins)
Open field

zone $\times$ genotype $P<0.0001$

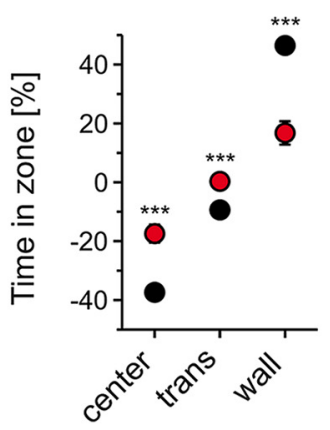

APLP2-KO

$\square \circ \mathrm{APP} \triangle \mathrm{CT} 15-\mathrm{DM}$

Figure 4. Impaired neuromuscular transmission and motor performance in APP $\Delta C T 15-D M$ mice. Mean MEPP frequency $(\boldsymbol{A})$ and amplitude $(\boldsymbol{B})$ reflecting spontaneous vesicle release are not affected in surviving APP $\Delta$ CT15-DM mice compared with APLP2-KO littermate controls. $\boldsymbol{C}-\boldsymbol{F}$, Evoked vesicle release. $\boldsymbol{C}$, Quantal content of APP $\Delta$ CT15-DM mice is not significantly altered. However, APP $\Delta$ CT15-DMs display a significantly decreased pool of readily releasable vesicles (ves.) (D) paralleled by an increased probability of vesicle release $(\boldsymbol{E})$. $\boldsymbol{E}$, Probability of release was calculated as the ratio of the quantal content of the first response of a train divided by the readily releasable pool of that synapse. $\boldsymbol{F}$, Endplate potentials were measured at six time points $(1,2,4,6,8$, and $10 \mathrm{~s})$ during a total stimulation period of $10 \mathrm{~s}$ (at $20 \mathrm{~Hz}$ ). For each data point, five responses occurring during a $200 \mathrm{~ms}$ window were averaged. The evoked postsynaptic responses in APP $\Delta C \mathrm{CT} 15-\mathrm{DM}$ mice were significantly $(p<0.05)$ reduced between 4 and 10 s of stimulation. Total number of myofibers and number of mice analyzed in A: APLP2-K0, $n=49 / 5$ (corresponding to 49 myofibers from 5 mice); APP $\Delta$ (T15-DM, $n=54 / 5$; in $B$ : APLP2-KO, $n=50 / 5 ;$ APP $\Delta$ CT15-DM, $n=54 / 5$; in C: APLP2-KO, $n=30 / 5 ;$ APP $\Delta$ CT15-DM, $n=54 / 5$; in D, E: APLP2-KO, $n=29 / 3 ;$ APP $\Delta$ CT15-DM, $n=$ 47/5; in $\boldsymbol{F}$ : APLP2-KO, $n=29 / 3 ;$ APP $\Delta$ CT15-DM, $n=46 / 5$. G, Significantly decreased grip strength of APP $\Delta$ CT15-DMs indicates impaired muscular performance. $\boldsymbol{H}$, Home cage activity of APP $\triangle$ CT15-DM mice was significantly increased during the dark but unaltered during the light phase. $I$, Exploratory behavior of mice was tested in a circular open field. In a new environment, the locomotion activity of APP $\triangle$ CT15-DM animals increased during 2 consecutive days, which differs from the habituation behavior of APLP2-K0 controls. J, In contrast to the WT-like zone preference of APLP2-K0s, APP $\triangle$ CT15-DM mice showed significantly reduced avoidance of the center and the transition (trans) zone. Number of mice analyzed in G: APLP2-K0, $n=17 ;$ APP $\Delta$ CT15-DM, $n=$ 15; and in $\boldsymbol{H}-\mathrm{J}$ : APLP2-KO, $n=17$; APP $\Delta C$ CT15-DM, $n=17$. Bars, circles, and squares represent mean \pm SEM. Statistical analysis was performed using Student's $t$ test in $\boldsymbol{A}-\boldsymbol{F}$ or ANOVA, genotype, $F_{(1,28)}=59.3, p<0.0001(G)$, phase $\times$ genotype, $F_{(1,30)}=50.7, p<0.0003(\boldsymbol{H})$, time $\times$ genotype, $F_{(3,90)}=40.4, p<0.0001(\boldsymbol{I})$, zone $\times$ genotype, $F_{(2,60)}=31.1, p<0.0001(\boldsymbol{J})$ with Tukey's post hoc test in $\mathbf{G}-\mathbf{J}:{ }^{* *} p<0.001,{ }^{* *} p<0.01$, n.S., not significant. Age at analysis: $\boldsymbol{A}-\boldsymbol{F}, \sim 6-8$ weeks; and $\mathbf{G}-\boldsymbol{J}, 5.5-7$ months. 
A

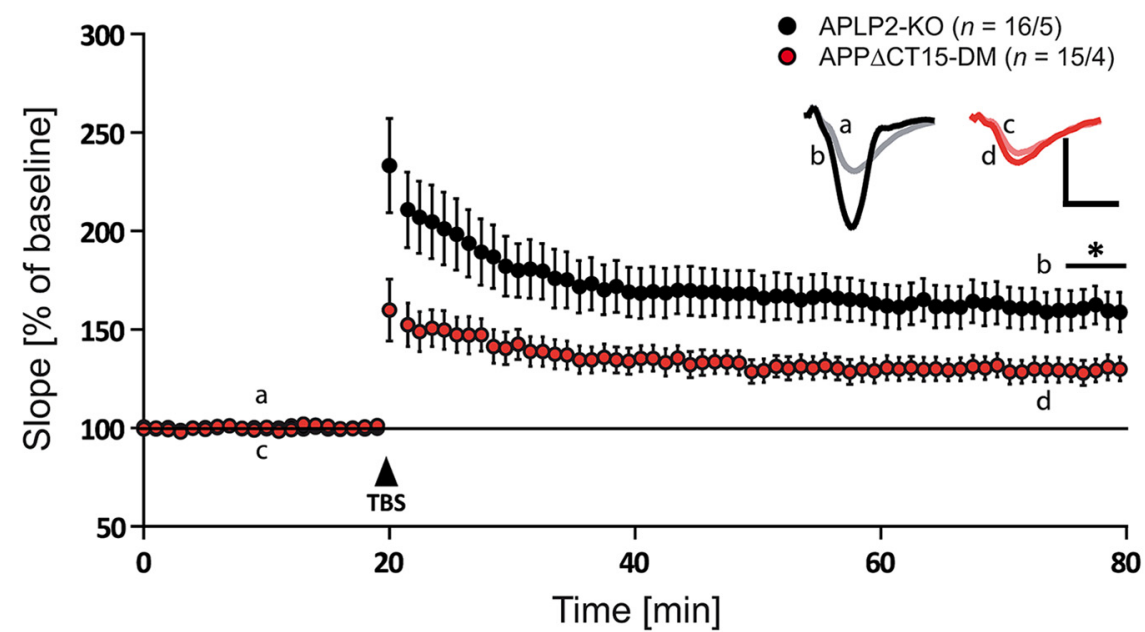

C

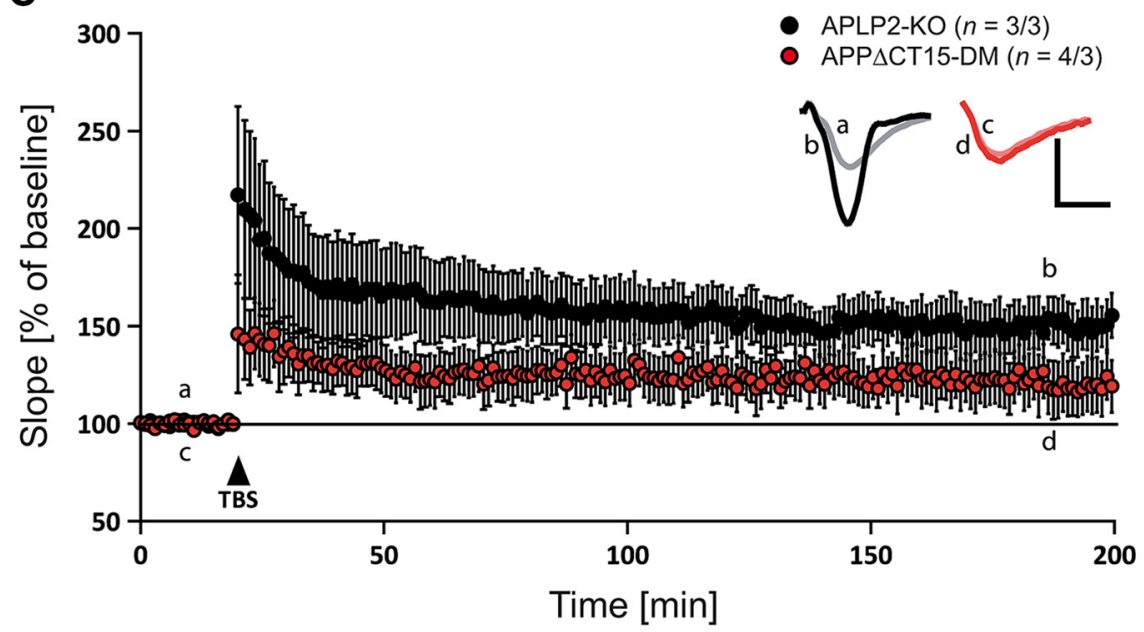

E

- APLP2-KO $(n=11 / 4)$ - $\operatorname{APP} \triangle \mathrm{CT} 15-\mathrm{DM}(n=10 / 3)$

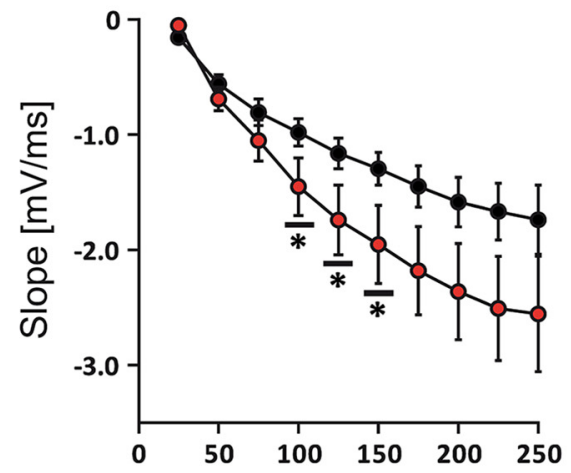

Stimulus intensities $[\mu \mathrm{A}]$
$\mathbf{F}$

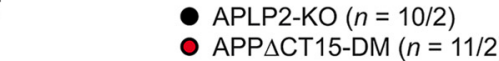

D

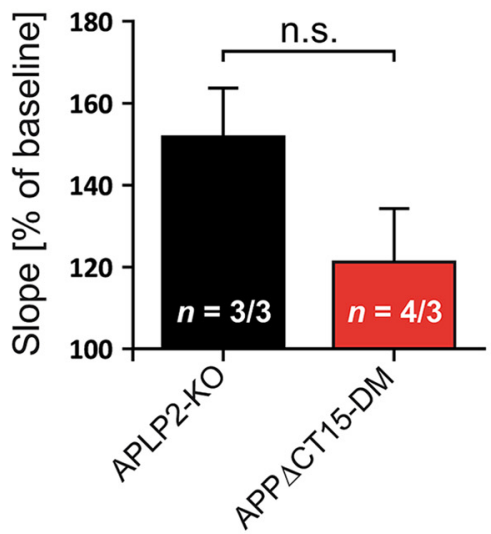

G

APLP2-KO $(n=15 / 5)$

- APP $\triangle \mathrm{CT} 15-\mathrm{DM}(n=14 / 4)$

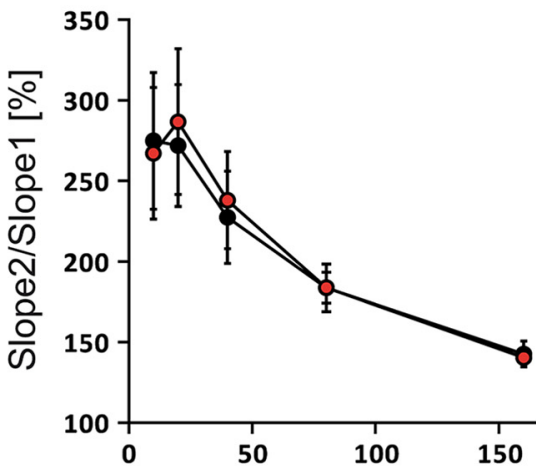

Interstimulus interval [ms]

Figure 5. APP $\Delta C T 15-D M$ mice display impaired synaptic plasticity. $A$, After 20 min of baseline recording, LTP was successfully induced by TBS (arrow). After TBS application, LTP is significantly impaired in APP $\Delta$ CT15-DMs (red circles) compared with littermate controls (black circles). $\boldsymbol{B}$, Average fEPSP values for the last 5 min of LTP recording. With a mean of $129 \pm 6.0 \%, A P P \Delta$ CT15-DMs show significantly lower potentiation levels than littermate controls with $160 \pm 9.7 \%$ ( $p=0.015$, Student's $t$ test). C, Recording time was prolonged to $3 \mathrm{~h}$ after TBS to investigate protein synthesis-dependent late-LTP. Progression of late-LTP displayed a trend comparable with LTP recordings. $\boldsymbol{D}$, However, no significant difference was observed between mean fEPSP values of APP $\Delta$ CT15-DMs and of littermate controls for the last 5 min of recording ( $p=0.215$, Student's $t$ test). $E$, APP $\Delta$ CT15-DM mice show significantly reduced input ouput (I0) strength at defined stimulus intensities of $100 \mu \mathrm{A}(p=0.046), 125 \mu \mathrm{A}(p=0.042)$, and $150 \mu \mathrm{A}(p=0.048$, Student's $t$ test). $\boldsymbol{F}$, The fEPSP slope of APP $\Delta$ CT15-DM animals was significantly steeper than that of APLP2-K0 mice at a fiber volley amplitude of $0.2 \mathrm{mV}$ ( $p=0.007$, Student's $t$ test). $\boldsymbol{G}$, APP $\Delta$ CT15-DMs show unaffected paired-pulse facilitation. $\boldsymbol{A}, \boldsymbol{C}$, Insets, Original traces of representative individual experiments. Calibration: vertical, $1 \mathrm{mV}$; horizontal, $5 \mathrm{~ms}$. Error bars indicate \pm SEM. Age at analysis: $\sim 9-12$ months. 
of the last $5 \mathrm{~min}$ was analyzed. Indeed, a similar trend was observed for APP $\Delta$ CT15-DM with $121 \pm 13.0 \%(n=4 / 3)$ and littermate control with $151 \pm 11.9 \%$ of potentiation $(n=3 / 3)$, although it did not reach significance (Fig. $5 C, D ; p=0.215, t$ test). To test whether the defect is accompanied by an altered basal synaptic transmission, we also measured input ouput (IO) strength. The correlation of the fEPSP slope to defined stimulus intensities (Fig. 5E) revealed a larger fEPSP slope in double mutants than in controls, which was significant at currents ranging from $100 \mu \mathrm{A}$ ( $p=0.046, t$ test), $125 \mu \mathrm{A}(p=0.042)$, to $150 \mu \mathrm{A}$ $(p=0.048)$. Comparable results were obtained when measuring the slope size at given fiber volley amplitudes (Fig. $5 F$ ). Again, the slope size was increased in relation to values from littermate controls over the complete measurement, although this difference became only significant for a fiber volley amplitude of $0.2 \mathrm{mV}$ ( $p=0.007, t$ test). As a second approach, the presynaptic functionality and short-term plasticity were probed by the paired-pulse facilitation paradigm. To this end, two pulses with defined interstimulus intervals were applied, and the ratio of the second to first slope was calculated, revealing no significant difference (Fig. 5G). Overall, this points to a postsynaptic, but not presynaptic defect, which might in turn affect LTP induction and maintenance.

As APP $\Delta$ CT15-DMs exhibit reduced muscle strength, we used dry mazes (instead of the Morris water maze) to study hippocampus-dependent behavior. To assess spatial working memory, mice underwent testing in the 8 -arm radial maze (Fig. $6 A-C)$. Whereas APLP2-KO littermate controls learned the test well and made on average 7 correct among the first 8 choices at the end of training, APP $\Delta$ CT15-DMs showed a significantly reduced performance with only 5 or 6 correct choices (Fig. $6 A$ ) after $10 \mathrm{~d}$ of training. Likewise, when collecting baits from the arms of the maze, the number of reentry errors into previously visited arms was much higher for APP $\Delta$ CT15-DMs (Fig. 6B). In both groups, the number of reentry errors increased with the number of baits already collected, reflecting the increasing working memory load, but in APP $\Delta$ CT15-DM mice this increase was significantly steeper (Fig. 6C). To examine whether performance of APP $\Delta$ CT15-DM mice on the radial maze was compromised by hyperactivity, we evaluated three error measures, which we expected to be increased as a result of hyperactive behavior: nonchoices (partial arm entries without the mouse placing all 4 paws into the arm), aborted choices (arm entries with the animal returning before reaching the bait area), and procedural errors (complete entries of a still baited arm without consuming the bait). These errors occurred in very low numbers mainly during the first $2 \mathrm{~d}$ and were not more frequent in APP $\Delta$ CT15-DM mice (data not shown). Nonchoices were even slightly more numerous in APLP2-KO controls (ANOVA genotype, $F_{(1,29)}=11.15$, $p<0.0023$ ) (data not shown). Also, in the T-maze, which assesses spontaneous alternation between two T-shaped arms, APP $\Delta$ CT15-DMs were severely impaired (Fig. 6D) and performed only at chance level. Finally, mice underwent testing in two species-typical hippocampus-dependent behaviors (nesting behavior and burrowing behavior), which have previously been shown to be severely impaired by hippocampal lesions (Deacon et al., 2002). In both tests, APP $\Delta$ CT15-DMs were drastically impaired (Fig. 6E,F). Together, we are providing converging evidence from four independent behavioral tests ( $\mathrm{T}$-maze, radial maze, and the tests for species specific behavior) for impairments in hippocampus-dependent behavior in APP $\Delta \mathrm{CT} 15-\mathrm{DM}$ mice. Collectively, these data indicate that lack of the APP-CT15 domain severely impairs synaptic plasticity and is associated with impairments in spatial working memory and hippocampusdependent behavior.

\section{Discussion}

The vast majority of studies of APP biology have focused on its role for $\mathrm{AD}$ pathogenesis. Accumulating evidence indicates, however, that loss of physiological APP-mediated functions may contribute to the clinical symptoms of disease, most notably synaptic dysfunction and loss of cognitive abilities (Taylor et al., 2008; Suh et al., 2013; Hick et al., 2015). As such, it is crucial to dissect which APP domain(s) and/or fragments mediate its various functions in the developing and adult nervous system. Here, we used a genetic approach and demonstrate that lack of the APP-CT15 domain on an APLP2-KO background affects postnatal viability and leads to defective neuromuscular synapse development and function. Moreover, we also demonstrate a crucial role of the APP-CT15 domain for postnatal PNS and CNS physiology, with APP $\Delta$ CT15-DM mice exhibiting synaptic deficits, including impaired LTP and behavioral deficits that indicate hippocampal dysfunction.

The analysis of large cohorts of offspring allowed us to clearly distinguish rescue effects due to expression of C-terminally truncated APP in APP $\Delta$ CT15-DM mice compared with the significantly lower survival rates of complete DKO mice. Depending on the genetic background, between $\sim 27 \%$ and $45 \%$ of APP $\Delta$ CT15-DM mice survived into adulthood. These survival rates closely resemble those of previously generated APPs $\alpha$-DM mice (Weyer et al., 2011) and thus identify the APP-CT15 domain as the crucial domain for proper neuromuscular function, which is a prerequisite for survival. Indeed, morphological defects of newborn APP $\triangle \mathrm{CT} 15-\mathrm{DM}$ and APP/APLP2-DKO mice were remarkably similar with comparable degrees of endplate widening, nerve terminal sprouting, reductions in presynaptic and postsynaptic area, and reduced apposition of presynaptic and postsynaptic specializations. Surviving adult APP $\Delta$ CT15-DM mice exhibited a large number of fragmented synapses, indicating a role of the APP-CT15 domain for postnatal NMJ maintenance, consistent with similar findings in APPs $\alpha$-DM mice (Weyer et al., 2011). Recordings of synaptic transmission at the diaphragm of adult APP $\triangle$ CT15-DM mice revealed deficits in the readily releasable pool and impaired sustained transmitter release upon repetitive stimulations that were also reflected in reduced grip force. Interestingly, electrophysiological impairments of APP $\triangle$ CT15-DM mice were less pronounced compared with APPs $\alpha$-DM mice that showed, in addition, severely reduced quantal content and altered MEPP frequencies, suggesting that other motifs (e.g., more membrane proximal regions or transmembrane APP anchoring) are also required for normal physiology. Overall, our studies indicate a requirement of the C-terminus for both early stages (synaptic patterning and nerve growth) of neuromuscular development and postnatal NMJ maturation and function.

What might be the mechanism how lack of the APP-CT15 domain leads to PNS and CNS deficits? Lack of the APP-CT15 domain may abolish the binding of and signaling mediated by interactors of the YENPTY motif, including Dab1, Shc, Grb, Mint/X11 proteins, and most notably Fe65 family proteins (Aydin et al., 2012; van der Kant and Goldstein, 2015), which may provide a link to Ena/VASP proteins involved in actin organization. In this regard, it is striking that Fe65/Fe65L1-DKO mice exhibit remarkably similar neuromuscular deficits characterized by reduced size and apposition of presynaptic and postsynaptic elements, fragmented synapse topology in adult mice, and grip strength deficits (Kins et al., 2015; S. Kins, personal communication), suggesting that an APP/APLP2/Fe65L1 complex may be 
A

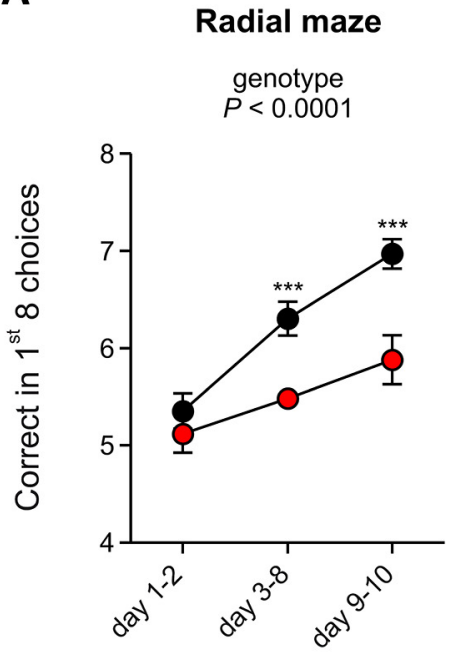

B

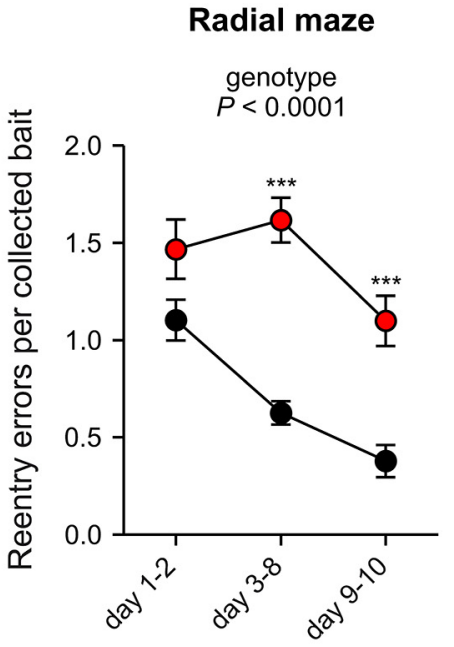

C

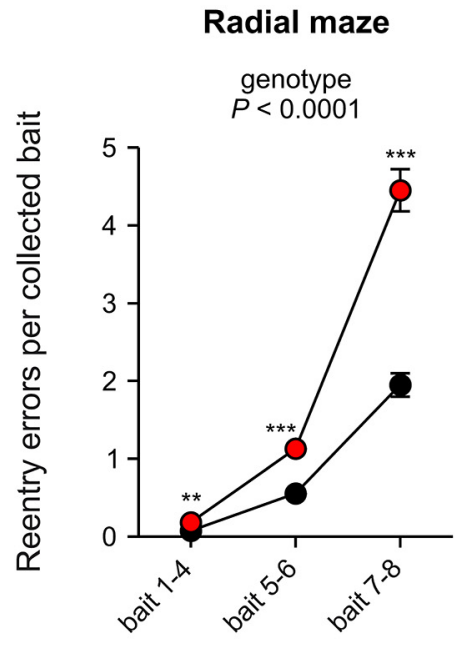

APLP2-KO -O- APP $\triangle C T 15-D M$

D

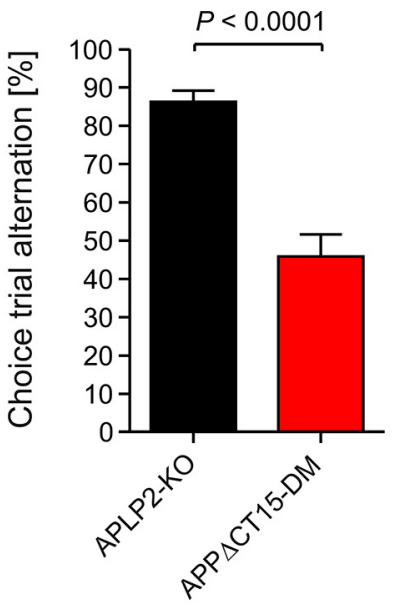

T-Maze
E

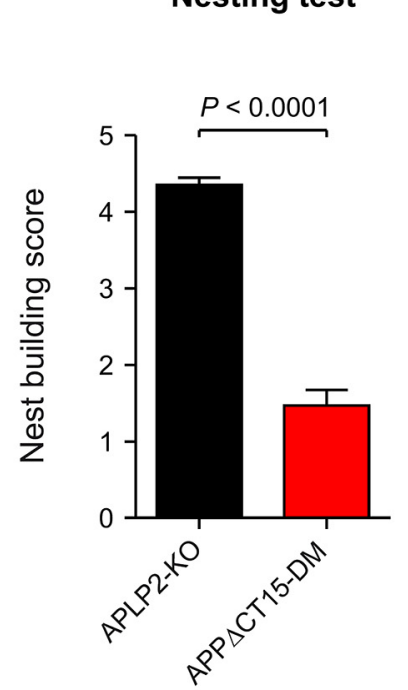

Nesting test
$\mathbf{F}$

\section{Burrowing test}

genotype $P<0.0001$

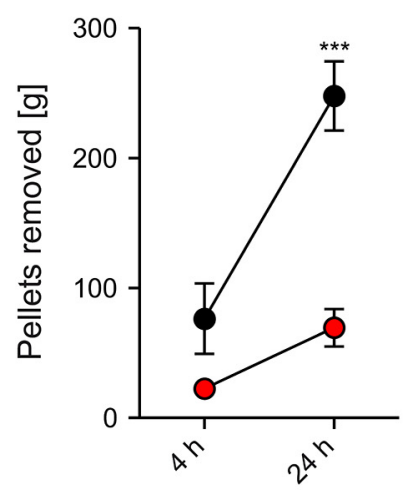

Figure 6. Hippocampus-related cognitive deficits and impaired species-typical behavior in APP $\Delta$ CT15-DM mice. Spatial working memory evaluated in the radial maze ( $\boldsymbol{A}-\boldsymbol{C})$. $\boldsymbol{A}, \mathrm{APP} \Delta \mathrm{CT15-DM}$ animals made fewer correct choices and showed less improvement during consecutive testing intervals. $\boldsymbol{B}$, To evaluate learning progress, reentry errors per collected bait were averaged within days and analyzed as a function of time. Double mutants made more errors per bait during days 3-10. C, To evaluate the impact of memory load on error number, reentry errors per collected bait were averaged across days and analyzed as a function of bait number. With increasing number of already collected baits, double mutant mice showed progressively higher error rates than control animals, indicating working memory deficits. D, APP $\Delta$ CT15-DMs show abolished spontaneous alternation in the T-maze, with $50 \%$ being the chance level. Alternation is calculated as the average percentage from 6 trials per genotype. $\boldsymbol{E}$, The ability to build nests was significantly impaired in APP $\Delta$ CT15-DMs. Scale: worst (1) to best (5) performance. $F$, APP $\Delta C$ CT15-DMs removed substantially less pellets than APLP2-K0 after 5 and $24 \mathrm{~h}$ of testing. Number of mice analyzed in $\boldsymbol{A}-\mathrm{C}$ : APLP2-K0, $n=16$; APP $\Delta$ CT15-DM, $n=17$; in D: APLP2-KO, $n=17$; APP $\Delta$ CT15-DM, $n=16$; in $E, F$ : APLP2-KO, $n=$ 17; APP $\Delta$ CT15-DM, $n=17$. Bars and circles represent mean \pm SEM. Statistical analysis was performed using ANOVA, genotype $F_{(1,29)}=30.6, p<0.0001(A)$, genotype $F_{(1,29)}=60.4, p<0.0001$ $(\boldsymbol{B})$, genotype $F_{(1,29)}=93.9, p<0.0001(\boldsymbol{C}), F_{(1,29)}=45.7, p<0.0001(\boldsymbol{D}), F_{(1,30)}=147, p<0.0001(\boldsymbol{E})$, genotype $F_{(1,30)}=20, p<0.0001(\boldsymbol{F})$. Tukey's posthoctest: ${ }^{* * *} p<0.001$, ${ }^{* *} p<0.01$. Age at analysis: $\sim 5.5-7$ months.

crucially involved in APP transmembrane signal transduction. Consistent with this model, APP ${ }^{\mathrm{Y} 682 \mathrm{G}}$ knockin abrogates Fe65 binding and newborn APP ${ }^{\mathrm{Y} 682 \mathrm{G}}$ APLP2-KO mice exhibited deficits in neuromuscular morphology (Barbagallo et al., 2011). It is also clear, however, that lack of Fe65 signaling alone cannot fully account for APP/APLP2 functions at the NMJ as lethality of APP/ APLP2-DKO mice is highly penetrant (e.g., 93\% on C57BL6 background), whereas the majority of Fe65/Fe65L1-DKO mice proved viable (Guénette et al., 2006). In turn, this implicates other interactors and/or APP domains as being required for proper NMJ function. Consistent with this, we and others have previously shown that APP binds Mint/X11 proteins, which may provide a functional link to Munc18 and thus the machinery for transmitter release (Weyer et al., 2011). Of note, the recently identified cytoplasmic $\mathrm{G}_{0}$ binding site that links APP to Akt signaling (Deyts et al., 2012; Ramaker et al., 2013; Milosch et al., 2014) is still present in APP $\Delta$ CT15 mutants, excluding a role of this pathway for NMJ deficits. 
Partial viability of DM mice also allowed us to investigate CNS functions. Although APP $\Delta \mathrm{CT} 15-\mathrm{KI}$ single mutants exhibit a WT-like phenotype (Ring et al., 2007), we show here that, in the absence of APLP2, the APP $\triangle C T 15$ variant is not sufficient to confer normal synaptic plasticity and behavior; this highlights again the importance of APLP2, which is often neglected in the $\mathrm{AD}$ field. The behavioral phenotype of APP $\Delta \mathrm{CT} 15-\mathrm{DM}$ w with defects in spatial working memory (impairments in T-maze and radial maze performance) indicates hippocampal dysfunction (Deacon and Rawlins, 2006), which is further supported by impaired species-typic behaviors (nesting and burrowing) that are highly sensitive to hippocampal lesions (Deacon et al., 2002). This notion is further supported by hyperactivity and lack of habituation in the open field (Roberts et al., 1962). Although basal synaptic transmission was largely normal, impaired hippocampus-dependent behaviors were also reflected in impairments in both the induction and maintenance of LTP. Normal short-term plasticity, assessed by paired-pulse facilitation, indicated that presynaptic functions, including transmitter release are normal, implicating postsynaptic defects as the major underlying cause of LTP deficits in APP $\triangle$ CT15-DM mutant mice. Recently, we observed impairments in paired-pulse facilitation (that may indicate a deficit in the control of presynaptic $\mathrm{Ca}^{2+}$ ) in NexCre cDKO mice completely lacking APP and APLP2 (Hick et al., 2015), suggesting that also extracellular and/or membrane domains of APP contribute to its presynaptic function. In addition, an upregulation of presynaptic L-type $\mathrm{Ca}^{2+}$ channels $\left(\mathrm{Ca}_{\mathrm{v} 1.2}\right)$ and altered short-term plasticity were found in GABAergic striatal APP-KO neurons (Yang et al., 2009). Thus, it appears that APP family proteins mediate crucial presynaptic and postsynaptic functions at both PNS and CNS synapses.

Overall, the phenotype of APP $\Delta$ CT15-DM mice closely resembles that of previously generated APPs $\alpha$-DM mice, which suggests an important role of APP transmembrane signaling for synaptic function. Consistently, recent analysis of Fe65-KO, Fe65L1-KO, and Fe65/Fe65L1-DKO mice also revealed similar CNS phenotypes, including defects in learning tasks and most notably LTP (Kins et al., 2015; S. Kins personal communication), strongly supporting the view that APP and Fe65 family proteins function in a common signaling pathway.

However, lack of the APP-CT15 domain not only abolishes binding of interactors, such as proteins of the Fe65 family, but also may indirectly affect APP physiology via altering the amounts/ratio of APP fragments being produced. Here, we unequivocally show that lack of the APP-CT15 domain strongly impairs $\mathrm{A} \beta$ generation in vivo, establishing the APP C-terminus as a target for $A \beta$ lowering strategies. Our findings of reduced amyloidogenic processing contrasts with previous studies of $\mathrm{APP} / \mathrm{hA} \beta /$ mutC knockin mice with C-terminal APP truncations (Li et al., 2010b) that were, however, confounded due to the cointroduction of three FAD-related mutations (Swedish, Arctic, and London), including the Swedish double mutation known to lead to highly elevated A $\beta$ levels. Given that young adult APP-KO mice lacking $\mathrm{A} \beta$ production are normal and that $\mathrm{APPs} \beta$ cannot rescue the lethality of APP/APLP2-DKO mice (Li et al., 2010a) and may even be neurotoxic (Nikolaev et al., 2009), we doubt that insufficient amyloidogenic APP processing causes the observed phenotypic abnormalities. The importance of the APP $\mathrm{C}$-terminus for APP processing is also evident from $\mathrm{APP}{ }^{\mathrm{Y} 682 \mathrm{G}}-\mathrm{KI}$ mice (that can no longer bind Fe65), which produce highly elevated APPs $\alpha$ levels (Barbagallo et al., 2010). Whereas young animals were normal, aged APP ${ }^{\mathrm{Y} 682 \mathrm{G}}$-KI mice developed impaired cognitive function and spine loss (Matrone et al., 2012), which may indicate a dominant negative role of the APP ${ }^{\mathrm{Y} 682 \mathrm{G}}$ mutation or that massive chronic overproduction of APPs $\alpha$ might have adverse effects.

Here, we show that APPs $\alpha$ production in APP $\Delta$ CT15-DM mice is not significantly altered compared with the phenotypically normal littermate controls, thus excluding potentially adverse effects due to APPs $\alpha$ overexpression. It is also conceivable, however, that the precise regulation of APPs $\alpha$ secretion at the synapse that occurs correlated with synaptic activity (Hoey et al., 2009; Hoe et al., 2012) may be lost in the absence of the APP-CT15 domain (and similarly also in APPs $\alpha$-DM mice). Several findings indicated that secreted APPs $\alpha$ is crucially involved in synaptic functions (Ishida et al., 1997; Meziane et al., 1998; Bour et al., 2004; Bell et al., 2008; Prox et al., 2013; Weyer et al., 2014). Notably, intracerebral infusion of APPs $\alpha$-specific antibodies or pharmacological inhibition of $\alpha$-secretase impaired LTP in adult rats (Taylor et al., 2008). Recently, to circumvent lethality due to neuromuscular impairments, we generated forebrain-specific APP/APLP2 double knock-out (cDKO) mice that exhibited reduced spine density, impaired LTP and hippocampus-dependent behaviors (Hick et al., 2015). Strikingly, the impairment of LTP of adult cDKO mice could be rescued by acute application of nanomolar amounts of recombinant APPs $\alpha$ (but not APPs $\beta$ ), indicating a crucial role for APPs $\alpha$ to support synaptic plasticity on a rapid time scale in adult brain (Hick et al., 2015). Clearly, more work, in particular the identification of the still elusive APPs $\alpha$ receptor, is needed to fully understand the precise synaptic role of the APP gene family. Consistent with our data, a recent study from Drosophila implicated both secreted APPLs (the fly homologs of APP) and a noncleavable transmembrane APPL isoform in memory formation (Bourdet et al., 2015). Collectively, these studies and our present analysis of APP $\triangle$ CT15-DM mice show the complex and multifaceted nature of APP/APLP physiological functions and indicate that not only secreted APPs $\alpha$ but also transmembrane APP signaling is required for normal PNS and CNS function, which needs to be taken into account when studying the pathophysiology of APP with respect to Alzheimer's disease.

\section{References}

Aydin D, Filippov MA, Tschäpe JA, Gretz N, Prinz M, Eils R, Brors B, Müller UC (2011) Comparative transcriptome profiling of amyloid precursor protein family members in the adult cortex. BMC Genomics 12:160. CrossRef Medline

Aydin D, Weyer SW, Müller UC (2012) Functions of the APP gene family in the nervous system: insights from mouse models. Exp Brain Res 217: 423-434. CrossRef Medline

Barbagallo AP, Weldon R, Tamayev R, Zhou D, Giliberto L, Foreman O, D'Adamio L (2010) Tyr(682) in the intracellular domain of APP regulates amyloidogenic APP processing in vivo. PLoS One 5:e15503. CrossRef Medline

Barbagallo AP, Wang Z, Zheng H, D'Adamio L (2011) A single tyrosine residue in the amyloid precursor protein intracellular domain is essential for developmental function. J Biol Chem 286:8717-8721. CrossRef Medline

Baumkötter F, Schmidt N, Vargas C, Schilling S, Weber R, Wagner K, Fiedler S, Klug W, Radzimanowski J, Nickolaus S, Keller S, Eggert S, Wild K, Kins S (2014) Amyloid precursor protein dimerization and synaptogenic function depend on copper binding to the growth factor-like domain. J Neurosci 34:11159-11172. CrossRef Medline

Bell KF, Zheng L, Fahrenholz F, Cuello AC (2008) ADAM-10 overexpression increases cortical synaptogenesis. Neurobiol Aging 29: 554-565. CrossRef Medline

Bour A, Little S, Dodart JC, Kelche C, Mathis C (2004) A secreted form of the beta-amyloid precursor protein (sAPP695) improves spatial recognition memory in OF1 mice. Neurobiol Learn Mem 81:27-38. CrossRef Medline 
Bourdet I, Preat T, Goguel V (2015) The full-length form of the Drosophila amyloid precursor protein is involved in memory formation. J Neurosci 35:1043-1051. CrossRef Medline

Caldwell JH, Klevanski M, Saar M, Müller UC (2013) Roles of the amyloid precursor protein family in the peripheral nervous system. Mech Dev 130:433-446. CrossRef Medline

Deacon RM (2006a) Burrowing in rodents: a sensitive method for detecting behavioral dysfunction. Nat Protoc 1:118-121. CrossRef Medline

Deacon RM (2006b) Assessing nest building in mice. Nat Protoc 1: 1117-1119. CrossRef Medline

Deacon RM, Rawlins JN (2006) T-maze alternation in the rodent. Nat Protoc 1:7-12. CrossRef Medline

Deacon RM, Croucher A, Rawlins JN (2002) Hippocampal cytotoxic lesion effects on species-typical behaviours in mice. Behav Brain Res 132: 203-213. CrossRef Medline

Deyts C, Vetrivel KS, Das S, Shepherd YM, Dupré DJ, Thinakaran G, Parent AT (2012) Novel GalphaS-protein signaling associated with membranetethered amyloid precursor protein intracellular domain. J Neurosci 32: 1714-1729. CrossRef Medline

Dunn KW, Kamocka MM, McDonald JH (2011) A practical guide to evaluating colocalization in biological microscopy. Am J Physiol Cell Physiol 300:C723-C742. CrossRef Medline

Elmqvist D, Quastel DM (1965) A quantitative study of end-plate potentials in isolated human muscle. J Physiol 178:505-529. CrossRef Medline

Guénette S, Chang Y, Hiesberger T, Richardson JA, Eckman CB, Eckman EA, Hammer RE, Herz J (2006) Essential roles for the FE65 amyloid precursor protein-interacting proteins in brain development. EMBO J 25: 420-431. CrossRef Medline

Heber S, Herms J, Gajic V, Hainfellner J, Aguzzi A, Rülicke T, von Kretzschmar H, von Koch C, Sisodia S, Tremml P, Lipp HP, Wolfer DP, Müller U (2000) Mice with combined gene knock-outs reveal essential and partially redundant functions of amyloid precursor protein family members. J Neurosci 20:7951-7963. Medline

Herms J, Anliker B, Heber S, Ring S, Fuhrmann M, Kretzschmar H, Sisodia S, Müller U (2004) Cortical dysplasia resembling human type 2 lissencephaly in mice lacking all three APP family members. EMBO J 23:41064115. CrossRef Medline

Hick M, Herrmann U, Weyer SW, Mallm JP, Tschäpe JA, Borgers M, Mercken M, Roth FC, Draguhn A, Slomianka L, Wolfer DP, Korte M, Müller UC (2015) Acute function of secreted amyloid precursor protein fragment APPsalpha in synaptic plasticity. Acta Neuropathol 129:21-37. CrossRef Medline

Hoe HS, Lee HK, Pak DT (2012) The upside of APP at synapses. CNS Neurosci Ther 18:47-56. CrossRef Medline

Hoey SE, Williams RJ, Perkinton MS (2009) Synaptic NMDA receptor activation stimulates alpha-secretase amyloid precursor protein processing and inhibits amyloid-beta production. J Neurosci 29:4442-4460. CrossRef Medline

Hornsten A, Lieberthal J, Fadia S, Malins R, Ha L, Xu X, Daigle I, Markowitz M, O'Connor G, Plasterk R, Li C (2007) APL-1, a Caenorhabditis elegans protein related to the human beta-amyloid precursor protein, is essential for viability. Proc Natl Acad Sci U S A 104:1971-1976. CrossRef Medline

Ishida A, Furukawa K, Keller JN, Mattson MP (1997) Secreted form of betaamyloid precursor protein shifts the frequency dependency for induction of LTD, and enhances LTP in hippocampal slices. Neuroreport 8: 2133-2137. CrossRef Medline

Kins S, Strecker P, Schilling S, Schmidt N, Baumkötter F, Herz J, Korte M, Ludewig S, Rust M, Eggert S, Guénette S (2015) Amyloid Precursor Protein synaptic function involves trans-dimerization and Fe65/Fe65L1 signaling. In: 12th international conference on Alzheimer's and Parkinson's diseases. Nice, France.

Klevanski M, Saar M, Baumkötter F, Weyer SW, Kins S, Müller UC (2014) Differential role of APP and APLPs for neuromuscular synaptic morphology and function. Mol Cell Neurosci 61C:201-210. CrossRef Medline

Kögel D, Deller T, Behl C (2012) Roles of amyloid precursor protein family members in neuroprotection, stress signaling and aging. Exp Brain Res 217:471-479. CrossRef Medline

Korte M, Herrmann U, Zhang X, Draguhn A (2012) The role of APP and APLP for synaptic transmission, plasticity, and network function: lessons from genetic mouse models. Exp Brain Res 217:435-440. CrossRef Medline

Laßek M, Weingarten J, Einsfelder U, Brendel P, Müller U, Volknandt W
(2013) Amyloid precursor proteins are constituents of the presynaptic active zone. J Neurochem 127:48-56. CrossRef Medline

Li H, Wang B, Wang Z, Guo Q, Tabuchi K, Hammer RE, Südhof TC, Zheng H (2010a) Soluble amyloid precursor protein (APP) regulates transthyretin and Klotho gene expression without rescuing the essential function of APP. Proc Natl Acad Sci U S A 107:17362-17367. CrossRef Medline

Li H, Wang Z, Wang B, Guo Q, Dolios G, Tabuchi K, Hammer RE, Südhof TC, Wang R, Zheng H (2010b) Genetic dissection of the amyloid precursor protein in developmental function and amyloid pathogenesis. J Biol Chem 285:30598-30605. CrossRef Medline

Li ZW, Stark G, Götz J, Rülicke T, Gschwind M, Huber G, Müller U, Weissmann C (1996) Generation of mice with a 200-kb amyloid precursor protein gene deletion by Cre recombinase-mediated site-specific recombination in embryonic stem cells. Proc Natl Acad Sci US A 93 6158-6162. CrossRef Medline

Madani R, Kozlov S, Akhmedov A, Cinelli P, Kinter J, Lipp HP, Sonderegger P, Wolfer DP (2003) Impaired explorative behavior and neophobia in genetically modified mice lacking or overexpressing the extracellular serine protease inhibitor neuroserpin. Mol Cell Neurosci 23:473-494. CrossRef Medline

Magara F, Müller U, Li ZW, Lipp HP, Weissmann C, Stagljar M, Wolfer DP (1999) Genetic background changes the pattern of forebrain commissure defects in transgenic mice underexpressing the beta-amyloid-precursor protein. Proc Natl Acad Sci U S A 96:4656-4661. CrossRef Medline

Matrone C, Luvisetto S, La Rosa LR, Tamayev R, Pignataro A, Canu N, Yang L, Barbagallo AP, Biundo F, Lombino F, Zheng H, Ammassari-Teule M, D’Adamio L (2012) Tyr682 in the Abeta-precursor protein intracellular domain regulates synaptic connectivity, cholinergic function, and cognitive performance. Aging Cell 11:1084-1093. CrossRef Medline

McLachlan EM, Martin AR (1981) Non-linear summation of end-plate potentials in the frog and mouse. J Physiol 311:307-324. CrossRef Medline

Meziane H, Dodart JC, Mathis C, Little S, Clemens J, Paul SM, Ungerer A (1998) Memory-enhancing effects of secreted forms of the beta-amyloid precursor protein in normal and amnestic mice. Proc Natl Acad Sci U S A 95:12683-12688. CrossRef Medline

Milosch N, Tanriöver G, Kundu A, Rami A, François JC, Baumkötter F, Weyer SW, Samanta A, Jäschke A, Brod F, Buchholz CJ, Kins S, Behl C, Müller UC, Kögel D (2014) Holo-APP and G-protein-mediated signaling are required for sAPPalpha-induced activation of the Akt survival pathway. Cell Death Dis 5:e1391. CrossRef Medline

Nikolaev A, McLaughlin T, O’Leary DD, Tessier-Lavigne M (2009) APP binds DR6 to trigger axon pruning and neuron death via distinct caspases. Nature 457:981-989. CrossRef Medline

Perez RG, Soriano S, Hayes JD, Ostaszewski B, Xia W, Selkoe DJ, Chen X, Stokin GB, Koo EH (1999) Mutagenesis identifies new signals for betaamyloid precursor protein endocytosis, turnover, and the generation of secreted fragments, including Abeta42. J Biol Chem 274:18851-18856. CrossRef Medline

Prox J, Bernreuther C, Altmeppen H, Grendel J, Glatzel M, D'Hooge R, Stroobants S, Ahmed T, Balschun D, Willem M, Lammich S, Isbrandt D, Schweizer M, Horré K, De Strooper B, Saftig P (2013) Postnatal disruption of the disintegrin/metalloproteinase ADAM10 in brain causes epileptic seizures, learning deficits, altered spine morphology, and defective synaptic functions. J Neurosci 33:12915-12928. CrossRef Medline

Ramaker JM, Swanson TL, Copenhaver PF (2013) Amyloid precursor proteins interact with the heterotrimeric $\mathrm{G}$ protein Go in the control of neuronal migration. J Neurosci 33:10165-10181. CrossRef Medline

Ring S, Weyer SW, Kilian SB, Waldron E, Pietrzik CU, Filippov MA, Herms J, Buchholz C, Eckman CB, Korte M, Wolfer DP, Müller UC (2007) The secreted beta-amyloid precursor protein ectodomain APPs alpha is sufficient to rescue the anatomical, behavioral, and electrophysiological abnormalities of APP-deficient mice. J Neurosci 27:7817-7826. CrossRef Medline

Roberts WW, Dember WN, Brodwick M (1962) Alternation and exploration in rats with hippocampal lesions. J Comp Physiol Psychol 55: 695-700. CrossRef Medline

Suh J, Choi SH, Romano DM, Gannon MA, Lesinski AN, Kim DY, Tanzi RE (2013) ADAM10 missense mutations potentiate beta-amyloid accumulation by impairing prodomain chaperone function. Neuron 80:385-401. CrossRef Medline

Taylor CJ, Ireland DR, Ballagh I, Bourne K, Marechal NM, Turner PR, Bilkey DK, Tate WP, Abraham WC (2008) Endogenous secreted amyloid pre- 
cursor protein-alpha regulates hippocampal NMDA receptor function, long-term potentiation and spatial memory. Neurobiol Dis 31:250-260. CrossRef Medline

van der Kant R, Goldstein LS (2015) Cellular functions of the amyloid precursor protein from development to dementia. Dev Cell 32:502-515. CrossRef Medline

von Koch CS, Zheng H, Chen H, Trumbauer M, Thinakaran G, van der Ploeg LH, Price DL, Sisodia SS (1997) Generation of APLP2 KO mice and early postnatal lethality in APLP2/APP double KO mice. Neurobiol Aging 18:661-669. CrossRef Medline

Wang P, Yang G, Mosier DR, Chang P, Zaidi T, Gong YD, Zhao NM, Dominguez B, Lee KF, Gan WB, Zheng H (2005) Defective neuromuscular synapses in mice lacking amyloid precursor protein (APP) and APP-Like protein 2. J Neurosci 25:1219-1225. CrossRef Medline

Wang Z, Wang B, Yang L, Guo Q, Aithmitti N, Songyang Z, Zheng H (2009) Presynaptic and postsynaptic interaction of the amyloid precursor protein promotes peripheral and central synaptogenesis. J Neurosci 29: 10788-10801. CrossRef Medline

Wentzell JS, Bolkan BJ, Carmine-Simmen K, Swanson TL, Musashe DT, Kretzschmar D (2012) Amyloid precursor proteins are protective in Drosophila models of progressive neurodegeneration. Neurobiol Dis 46: 78-87. CrossRef Medline
Weyer SW, Klevanski M, Delekate A, Voikar V, Aydin D, Hick M, Filippov M, Drost N, Schaller KL, Saar M, Vogt MA, Gass P, Samanta A, Jäschke A, Korte M, Wolfer DP, Caldwell JH, Müller UC (2011) APP and APLP2 are essential at PNS and CNS synapses for transmission, spatial learning and LTP. EMBO J 30:2266-2280. CrossRef Medline

Weyer SW, Zagrebelsky M, Herrmann U, Hick M, Ganss L, Gobbert J, Gruber M, Altmann C, Korte M, Deller T, Müller UC (2014) Comparative analysis of single and combined APP/APLP knockouts reveals reduced spine density in APP-KO mice that is prevented by APPsalpha expression. Acta Neuropathol Commun 2:36. CrossRef Medline

Wilhelm BG, Mandad S, Truckenbrodt S, Kröhnert K, Schäfer C, Rammner B, Koo SJ, Claßen GA, Krauss M, Haucke V, Urlaub H, Rizzoli SO (2014) Composition of isolated synaptic boutons reveals the amounts of vesicle trafficking proteins. Science 344:1023-1028. CrossRef Medline

Wolfer DP, Lipp HP (2000) Dissecting the behaviour of transgenic mice: is it the mutation, the genetic background, or the environment? Exp Physiol 85:627-634. CrossRef Medline

Yang L, Wang Z, Wang B, Justice NJ, Zheng H (2009) Amyloid precursor protein regulates Cav1.2 L-type calcium channel levels and function to influence GABAergic short-term plasticity. J Neurosci 29:15660-15668. CrossRef Medline 